\title{
Long-Term Average Performance Benefits of Parabolic Trough Improvements
}

Randy Gee

Harry W. Gaul

David Kearney

Ari Rabl
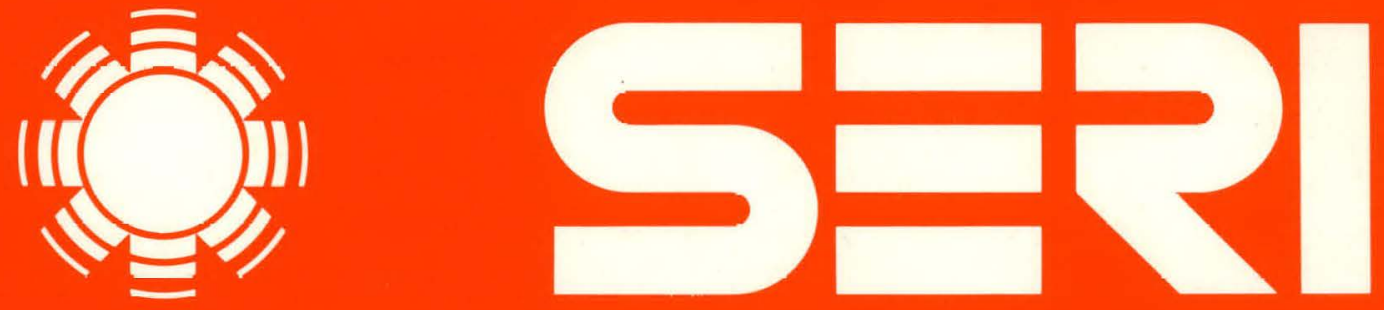

Solar Energy Research Institute

A Division of Midwest Research Institute

1617 Cole Boulevard

Golden, Colorado 80401

Operated for the

U.S. Department of Energy

under Contract No. EG-77-C-01-4042 


\section{DISCLAIMER}

This report was prepared as an account of work sponsored by an agency of the United States Government. Neither the United States Government nor any agency Thereof, nor any of their employees, makes any warranty, express or implied, or assumes any legal liability or responsibility for the accuracy, completeness, or usefulness of any information, apparatus, product, or process disclosed, or represents that its use would not infringe privately owned rights. Reference herein to any specific commercial product, process, or service by trade name, trademark, manufacturer, or otherwise does not necessarily constitute or imply its endorsement, recommendation, or favoring by the United States Government or any agency thereof. The views and opinions of authors expressed herein do not necessarily state or reflect those of the United States Government or any agency thereof. 


\section{DISCLAIMER}

Portions of this document may be illegible in electronic image products. Images are produced from the best available original document. 
Printed in the United States of America Available from:

National Technical Information Service

U.S. Department of Commerce

5285 Port Royal Road

Springfield, VA 22161

Price:

Microfiche $\$ 3 . \overline{00}$

Printed Copy

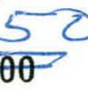

Price:

\section{NOTICE}

This report was prepared as an account of work sponsored by the United States Government. Neither the United States nor the United States Department of Energy, nor any of their employees, nor any of their contractors, subcontractors, or their employees, makes any warranty, express or implied, or assumes any legal liability or responsibility for the accuracy, completeness or usefulness of any information, apparatus, product or process disclosed, or represents that its use would not infringe privately owned rights. 
SERI/TR-632-439

UC CATEGORY: UC-59b

LONG-TERM AVERAGE PERFORMANCE BENEFITS OF PARABOLIC TROUGH IMPROVEMENTS

R. GEE

H. W. GAUL

D. KEARNEY

A. RABL

MARCH $1980^{\circ}$

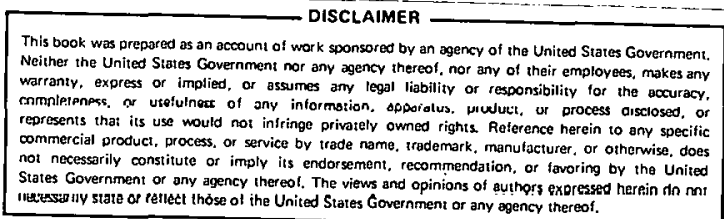

PREPARED UNDER TASK NO. 3471.20

\section{Solar Energy Research Institute}

1536 Cole Boulevard

Golden, Colorado 80401

A Division of Midwest Research Institute

Prepared for the

U.S. Department of Energy

Contract No. EG.77.C.01.4042 
THIS PAGE

WAS INTENTIONALLY

LEFT BLANK 
This work was prepared under DOE task 3471.20. The authors thank the many individuals from Sandia Laboratories' Solar Energy Projects Department and the Materials Branch of SERI who supported this project. Special thanks go to Dr. Gideon Yekutiell of the Weizmann Institute of Science, Israel, for his assistance and recommendations.

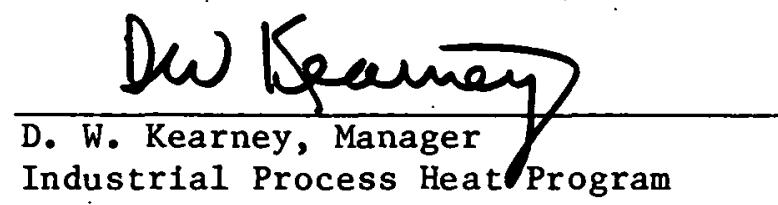

Approved for:

SOLAR ENERGY RESEARCH INSTITUTE

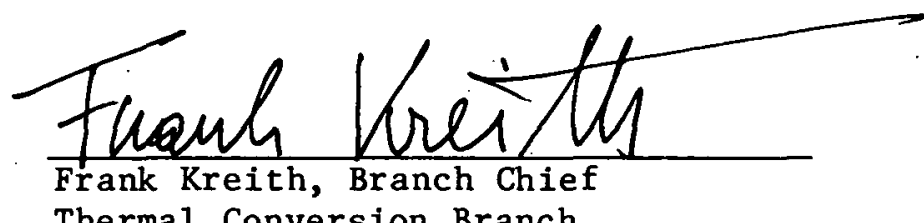

Thermal Conversion Branch

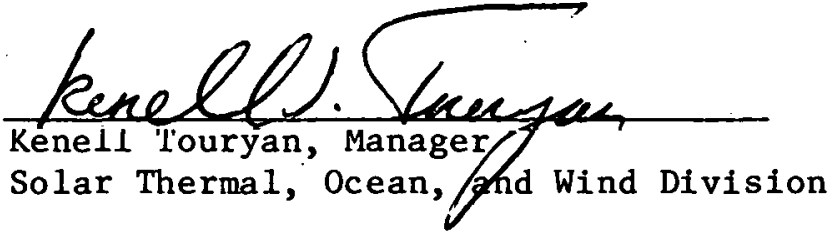


THIS PAGE

WAS INTENTIONALLY

LEFT BLANK 
SUMMARY

Improved parabolic trough concentrating collectors will result from better design, improved fabrication techniques, and the development and utilization of improved materials. The difficulty of achieving these improvements varies, as does their potential for increasing parabolic trough performance. The purpose of this analysis is to quantify the relative merit of various technology advancements in improving the long-term average performance of parabolic trough concentrating collectors.

Parabolic trough optical and thermal performance has been modeled in detall. This detailed parabolic trough model is used in conjunction with a utilizability method to predict energy delivery based on long-term average meteorological correlations. Using this methodology, the long-term performance benefits of improvements are determined as a function of operating temperature for north-south, east-west, and polar mounted parabolic troughs. The results are presented in graphical form to allow a quick determination of the performance merits of particular improvements. Substantial annual energy gains are shown to be attainable with improved parabolic troughs. The performance benefit resulting from an improvement is shown to be strongly dependent on operating temperature. Of the improvements evaluated, the development of stable backsllvered glass reflective surfaces offers the largest performance gain for operating temperatures below $150^{\circ} \mathrm{C}$. Above $150^{\circ} \mathrm{C}$, the development of trough receivers that can maintain a vacuum is the most significant potential improvement. The reduction of concentrator slope errors also has a substantial performance benefit at high operating temperatures. 
THIS PAGE

WAS INTENTIONALLY

LEFT BLANK 
TABLE OF CONTENTS

Page

$1.0 \quad$ Introduction $\ldots \ldots \ldots \ldots \ldots \ldots \ldots \ldots \ldots \ldots \ldots \ldots \ldots \ldots \ldots \ldots \ldots \ldots \ldots \ldots \ldots \ldots$

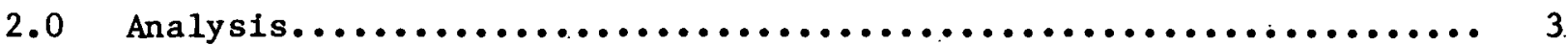

2.1 Methodology................................. 3

2.2 Reference Parabolic Trough and Potential Improvements........ 3

2.3 Thermal Analysis................................... 6

2.4 Optimization of Geometric Concentration Ratio.............. 10

2.5 optical Analysis................................. 12

2.6 Yearly Performance Prediction......................... 13

$3.0 \quad \operatorname{Results} . \ldots \ldots \ldots \ldots \ldots \ldots \ldots \ldots \ldots \ldots \ldots \ldots \ldots \ldots \ldots \ldots \ldots \ldots \ldots \ldots \ldots \ldots$

3.1 Individual Improvements........................... 15

3.2 Combined Improvements............................... 19

3.3 Validation of Method.............................. 20

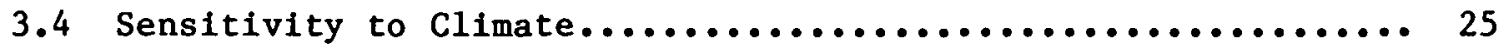

3.5 Discussion..................................... 28

$4.0 \quad$ References.......................................... 31

Nomenclature............................................ 33 
LIST OF FIGURES

Page

2-1 . Parabolic Trough Energy Delivery Model.................... 4

2-2 Heat-Loss Coefficients vs. Temperature..................... 8

2-3 Heat-Loss Coefficient Variance with Absorber Diameter............ 9

2-4 Heat-Ľoss Coeff́ficient vs. Gap Size...................... 9

3-1 Normalized Performance Index for Improved East-West Rotational Axis Parabolic Troughs.............................. 16

3-2 Normalized Performance Index for Improved North-South Rotational Axis Parabolic Troughs.............................. 17

3-3 Normalized Performance Index for Improved Polar Axis Parabolic Troughs....................................... 18

3-4 Annual Collection Efficiency for East-West Rotational Axis Parabolic Trough.................................. 21

3-5. Annual Collection Efficiency for North-South Rotational Axis Parabolic Trough................................... 22

3-6 Annual Collection Efficlency for Polar Axis Trough............ 23

3-7 Parabolic Trough Performance Gains with Combined Improvements...... 24

3-8 Error Bars for Three Collector Improvements Generated from Comparison of Utilizability Method to TMY Data.............. 26

3-9 Error Bars for Sensitivity of Normalized Performance Index to Latitude........................................ 27

3-10 Error Bars for Sensitivity of Normalized Performance Index to Clearness Index..................................... 29

\section{LIST OF TABLES}

3-1 Available Insolation Relative Error (\%) of Utilizability Method with Respect to TMY Data............................ 
SECTION 1.0

INTRODUCTION

Parabolic trough solar concentrators are capable of supplying thermal energy over a wide range of temperatures (up to about $350^{\circ} \mathrm{C}$ ) and presently are the leading solar technology in the intermediate temperature range. Although several manufacturers offer models for immediate application, opportunities exist to improve both the materials and mechanical components of troughs to achieve significant advancements in energy delivery, cost reduction, durability, and reliability. The impetus for this study was the need to reassess, in the light of current trough technology, the relative technical merit of improvements that are now possible or would require only moderate development. The potential improvements considered in the study pertain to receiver selective coating, reflector properties; and receiver glazing modifications.

Important to this study was the efficient calculational method developed by Collares-Pereira and Rabl [1] to predict annual collector energy delivery at a specified location. Collectors are often compared on the basis of peak efficiency curves; a more meaningful basis of comparison is the annual energy delivery, because it accounts for the influences of off-peak performance and weather varlations. As will be seen, off-normal insolation is also accounted for with modifications in the material properties and intercept factor as a function of incidence angle.

The objective of this study is to quantify the influence of various possible parabolic trough improvements over a wide range of design parameters. To assess the generality of the collector results, analyses were carried out for different cities. As a further check, a comparison of results was made using both the simplified annual energy delivery method and an hour-by-hour calculation with TMY meteorological data.

This report describes the essential features of the analytical method and the basis for the selections of reference and improved collector characteristics. Next, the performance results are presented and discussed, and conclusions are drawn concerning the importance of the postulated improvements. Work subsequent to this report will attempt to take into account the cost of the improvements, so that the benefits can be assessed on an economic basis. 


\section{SEPI*}




\section{SECTION 2.0}

ANALYSIS

\subsection{METHODOLOGY}

Parabolic trough annual energy delivery is calculated with a detailed model of optical and thermal parabolic trough characteristics in conjunction with a utilizability method that was based on long-term average meteorological correlations. The utilizability method is expedient and also accounts for longterm weather behavior. A detailed consideration of parabolic trough thermal and optical characteristics ensures that optical improvements and thermal improvements can be validly compared.

Fig. 2-l illustrates how parabolic trough annual energy. delivery is calculated. A key element of the calculation is optimization of the concentration ratio. The optimum geometric concentration ratio is the ratio that best balances optical losses with thermal losses. Over the temperature range that this study addresses, $50^{\circ} \mathrm{C}$ to $350^{\circ} \mathrm{C}$, the optimum concentration ratio of a parabolic trough varies significantly. Thus, parabolic trough performance is evaluated in this study for the geometric concentration ratio, at each operating temperature, that maximizes annual energy delivery.

The results of this analysis are presented in two forms. First, eight potentially attractive improvements are evaluated. A reference parabolic trough is defined, based on available materials and current technology, and is typical of commercially available parabolic trough concentrating collectors. Each of the eight improvements then define an improved parabolic trough. The annual energy delivery of each improved trough is normalized with respect to the annual energy delivery of the reference trough at the same operating temperature. This ratio of energy delivery is defined as the normalized performance index (NPI). The graphical presentation of normalized performance index versus operating temperature provides an easy determination of the effectiveness of each improvement relative to present technology.

Performance increase results are also shown graphically in a manner that is independent of our reference trough assumptions. The annual collection efficiency of parabolic troughs is defined as a function of receiver heat loss, optical errors, peak reflectance-transmittance-absorptance product, and tracking orientation. These graphs allow the determination of the annual collection efficiency increase resulting from one or several improvements.

\subsection{REFERENCE PARABOLIC TROUGH AND POTENTIAL IMPROVEMENTS}

Eight potentially. improved troughs are evaluated relative to a reference parabolic trough. The reference trough is representative of commercially available parabolic troughs. Most commercially available trough concentrators have rim angles at or near $90^{\circ}$, with second-surface aluminized-film reflectors. Typical commercially available trough receivers utilize a cylindrical glass tube surrounding an absorber tube with a black-chrome selective coating. Trough component characteristics have been compiled from collector performance 


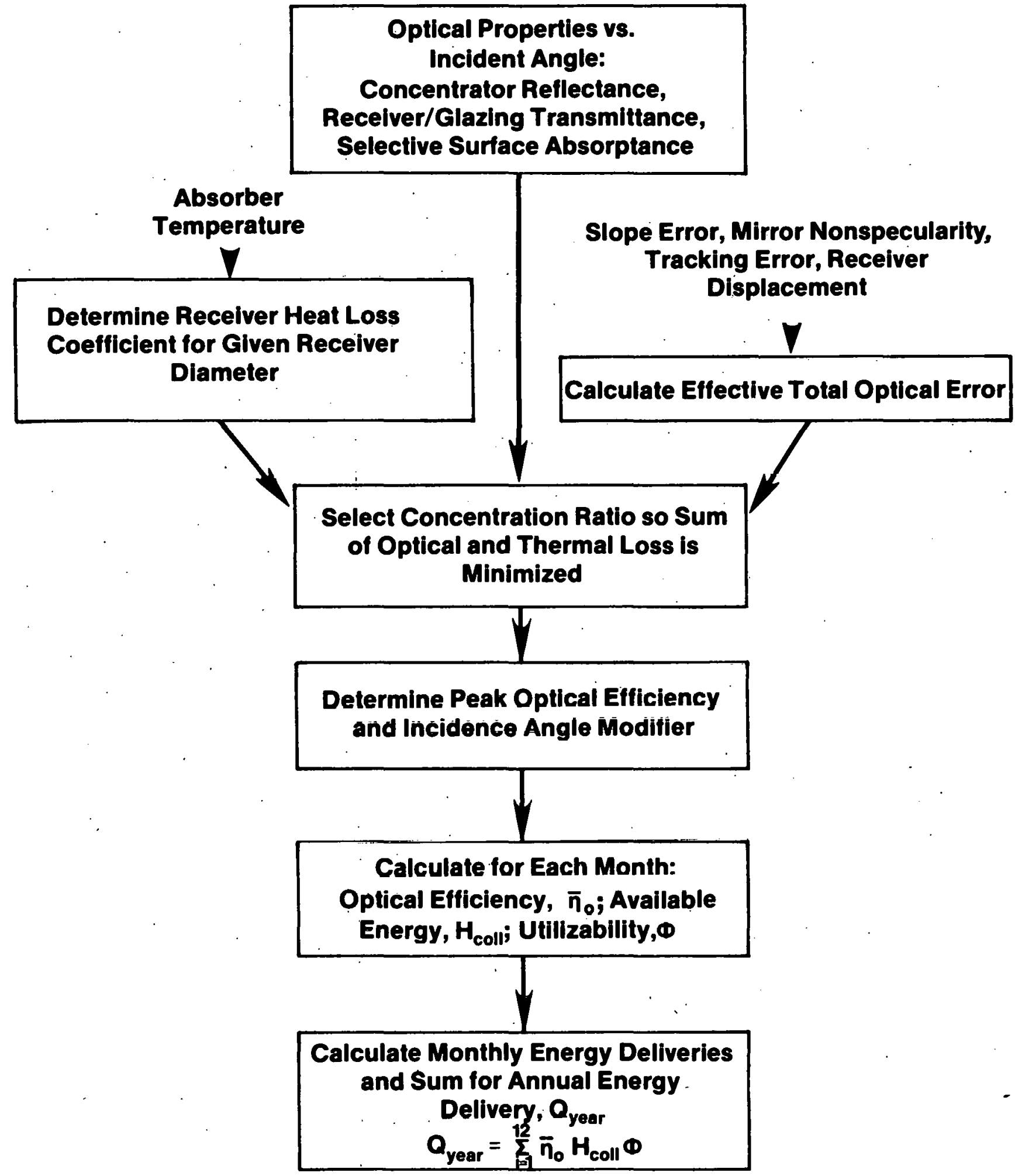

Figure 2-1. Parabolic Trough Energy Delivery Model 
tests and accelerated aging tests of trough materials [2-6]. Reference trough parameters are:

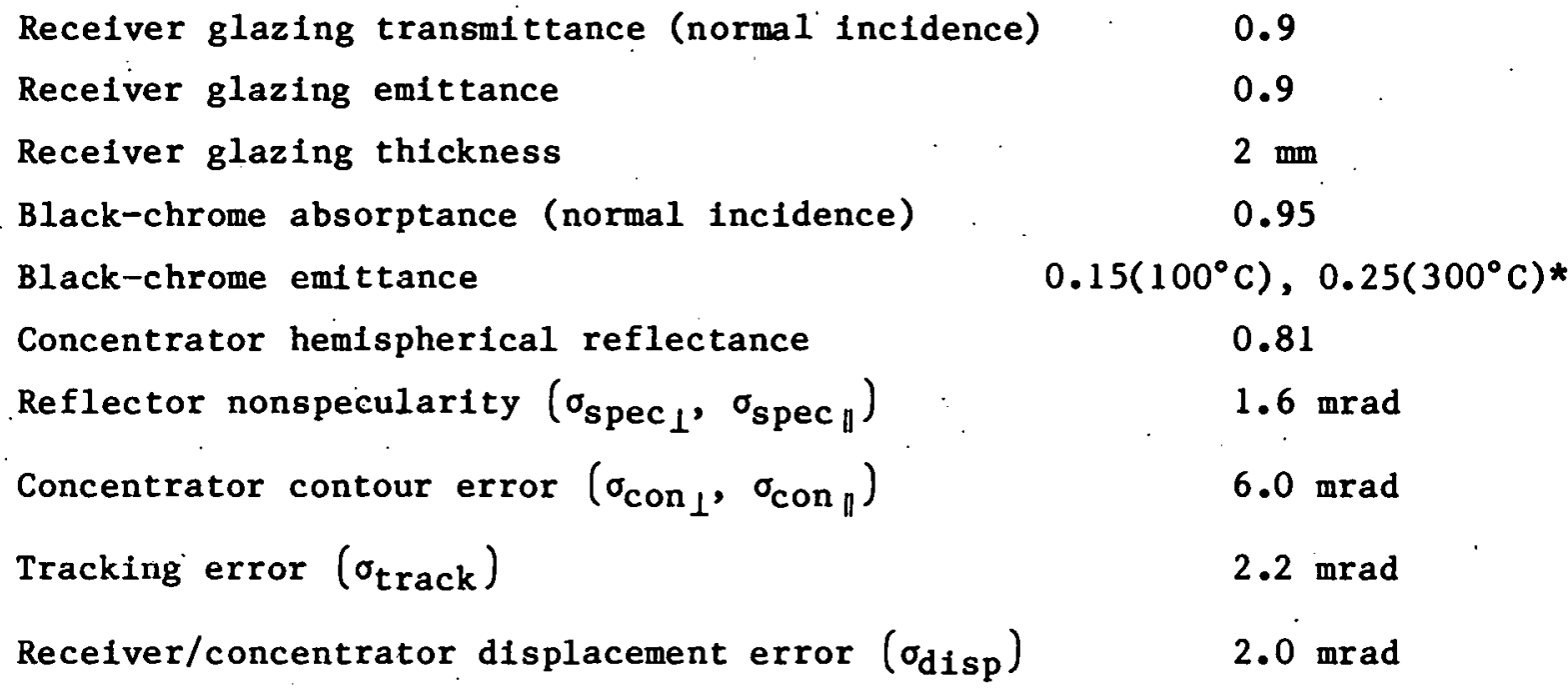

Eight improved parabolic troughs are defined based on the following potential improvements:

(1) Selective coating absorptance increase to 0.98 ;

(2) Selective coating emittance decreased to $0.05\left(100^{\circ} \mathrm{C}\right), 0.15\left(300^{\circ} \mathrm{C}\right) *$;

(3) Back-silvered glass reflector--reflectance increased to 0.95 , reflector nonspecularity decreased to $0.5 \mathrm{mrad}$;

(4) Concentrator slope error reduced to $3 \mathrm{mrad}$;

(5) Evacuated annulus receiver;

(6) Xenon back-filled annulus receiver;

(7) Heat mirror coated receiver glazing (glazing inner surface emittance $=0.15$, transmittance $=0.94) ;$ and

(8) Receiver glazing transmittance increased to 0.96.

All of these improvements can be considered near-term possibilities. Ef forts are underway to increase solar mirror reflectance through the development of stable, low-cost, back-silvered, thin glass mirrors. On the other hand, less effort is being directed at defining and diminishing concentrator slope errors. Slope error reductions could result from the use of precision molds, the development of new concentrator fabrication techniques, or the development of higher-stability concentrator substrates. Techniques to increase the transmittance of glass have been developed for flat-plate collectors. Antireflection coating and etching processes could be adapted to cylindrical linefocus receiver glazings. Selective surface coating development is being actively pursued. Black-chrome bath compositions, plating times and currents

*Black-chrome emittance assumed linear between and beyond these limits. 
are being investigated to improve thermal stability and optical characteristics. Various other coatings are also being developed--some with the potential for very low emittance and therefore reduced receiver heat losses. Other means of decreasing receiver heat losses are receiver glazings coated with heat mirrors and evacuated and back-filled receivers. Back-filled receivers involve filling the annulus between the absorber and surrounding glass with a low-conductivity gas to reduce conduction and convection losses. Development of a parabolic trough receiver that can maintain a vacuum has also been investigated [7]. Evacuation of the absorber-glass annulus to $10^{-3}$ torr effective1y eliminates conduction and convection within the annulus. A heat mirror coating on the inside surface of the reseiver glazing reduces radiation losses from the absorber because of the reduced effective emittance of the glass. However, the solar transmission through the receiver is dccreased by tile film's transmittance. The amount that improvements 2, 5, 6, and 7 decrease receiver heat loss is illustrated in Section 2.3.

This analysis defines improved performance on a long-term average basis. Therefore long-term average effects of accumulated dirt and dust must be taken into account. A long-term average dirt and dust degradation of $6 \%$ is included as a modifier to both the concentrator reflectance and glazing transmittance for the reference and improved troughs.

\subsection{THERMAL ANALYSIS}

A thermal model is used to predict heat losses from 1ine-focus parabolic trough receivers. Heat-loss coefficients are determined as a function of average absorber tube temperature. Relating heat loss to average absorber tube temperature eliminates the need to specify the fluid inlet or outlet temperature, flow rate, and fluid properties.

The one-dimensional (radial) model assumes the receiver is in steady state and that the absorber tube and glass envelope are gray and diffuse thermal radiation emitters and absorbers. The heat-loss rate from the absorber tube, $\dot{Q}_{\text {Loss }}$, is found by the iterative solution of these equations:

$$
\begin{aligned}
& \dot{Q}_{\text {Loss }}=\dot{Q}_{\text {abs,rad }}+\dot{Q}_{\text {abs,cond/conv }}=\dot{Q}_{\text {glass,cond }} \\
& \dot{\dot{Q}}_{\text {glass,abs }}+\dot{Q}_{\text {glass, cond }}=\dot{Q}_{\text {envir, cond }}+\dot{Q}_{\text {envir, rad }}
\end{aligned}
$$

where:

$$
\begin{aligned}
& \dot{Q}_{\text {abs,rad }}=\text { radiative heat-loss rate from absorber tube to glazing; } \\
& \begin{aligned}
\dot{\mathrm{Q}}_{\mathrm{abs}, \mathrm{cond} / \mathrm{conv}}= & \text { conductive/convective heat-loss rate from absorber tube } \\
& \text { to glazing; }
\end{aligned} \\
& \dot{Q}_{\text {glass,cond }}=\text { conductive heat-loss rate through glazing; } \\
& \dot{Q}_{\text {glass,abs. }} \text { rate of heat input into receiver glazing due to solar ab- }
\end{aligned}
$$




$$
\begin{aligned}
\dot{Q}_{\text {envir,conv }}= & \text { convective heat-loss rate from glazing to environment; } \\
\text { and } & \\
\dot{Q}_{\text {envir,rad }}= & \text { radiative heat-loss rate from glazing to environment. }
\end{aligned}
$$

Each heat transfer rate term is described in detail below per unit length of receiver:

$$
\begin{gathered}
\quad \frac{\dot{Q}_{\text {abs,rad }}}{\ell}=\frac{\pi D_{\text {abs }} \sigma\left(T_{\text {abs }}{ }^{4}-T_{\text {glass }, 1}{ }^{4}\right)}{\frac{1}{\varepsilon_{\text {abs }}}+\frac{D_{\text {abs }}}{D_{\text {glass, }}} \frac{1}{\varepsilon_{\text {glass }, 1}}-1} \\
\frac{\dot{Q}_{\text {abs,cond/conv }}}{\ell}=\overline{N u} \pi \mathrm{K}_{\text {gas }}\left(\mathrm{T}_{\text {abs }}-T_{\text {glass , } 1}\right)
\end{gathered}
$$

where $\overline{\mathrm{Nu}}=$ combined conductive/convective Nusselt number [8]:

$$
\begin{aligned}
& \frac{\dot{Q}_{\text {glass,cond }}}{\ell}=\frac{2 \pi K_{\text {glass }}}{\ln \frac{D_{\text {glass }, 0}}{D_{\text {glass }, 1}}}\left(T_{\text {glass }, 1}-T_{\text {glass , } 0}\right) \\
& \frac{\dot{Q}_{g l a s s, a b s}}{\ell}=\alpha_{\text {glass }} I_{b} \rho \mathrm{W} \\
& \frac{\dot{\mathrm{Q}}_{\text {envir,conv }}}{\ell}=\pi \mathrm{K}_{\text {air }} \mathrm{Nu} \text { wind }\left(\mathrm{T}_{\text {glass }, 0}-\mathrm{T}_{\text {amb }}\right) \text {, }
\end{aligned}
$$

where $\mathrm{Nu}_{\text {wind }}=$ wind velocity induced Nusselt number [9]:

$$
\frac{\dot{Q}_{\text {envir,rad }}}{\ell}=\varepsilon_{\text {glass, } 0} \pi \mathrm{D}_{\text {glass , o }} \sigma\left(\mathrm{T}_{\text {glass, } 0}{ }^{4}-\mathrm{T}_{\text {sink }}{ }^{4}\right)
$$

The properties of air, glass, annulus gas, and black chrome are computed as a function of their temperature. The term $Q_{g l a s s, a b s}$ is a function of beam insolation and therefore varies during the day. However, the sensitivity of the heat loss coefficient to this term is small and is therefore assumed constant to simplify the results. A wind velocity of $2 \mathrm{~m} / \mathrm{s}(4.5 \mathrm{mph})$ over the recelver is also assumed as representative of average wind conditions. 
Receiver heat loss can be expressed as a heat-loss coefficient, $U_{L}$, that is based on absorber tube surface area. Receiver heat-loss is related to $U_{L}$ by the following equation:

$$
\dot{\mathrm{Q}}_{\text {Loss }}(\text { watts })=\mathrm{U}_{\mathrm{L}} \pi \mathrm{D}_{\mathrm{abs}} \ell\left(\mathrm{T}_{\mathrm{abs}}-\mathrm{T}_{\mathrm{amb}}\right) \text {. }
$$

Figure 2-2 shows the solution of the heat rate equations for the reference trough receiver, the evacuated receiver, the xenon back-filled receiver, the heat mirror coated receiver glazing, and the reduced emittance selective coating receiver.

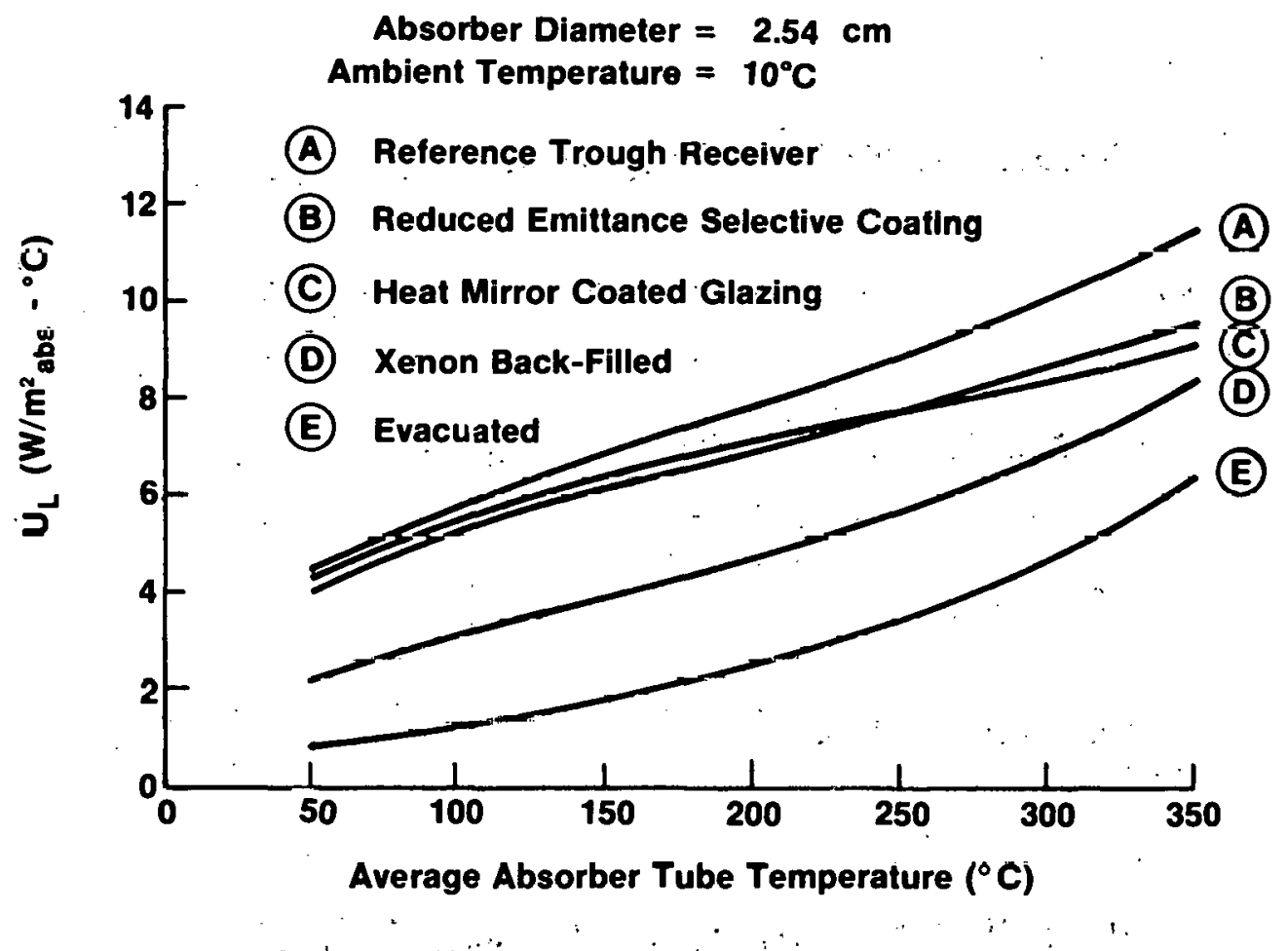

Figure 2-2. Heat-Loss Coefficients vs. Temperature

For thio otudy, the aboorbcr tube diameter io held conotant at $2.54 \mathrm{~cm}$. Different absorber tube diameters will result in only slightly different heatloss coefficients when they are.based on absorber tube surface area. Figure 2-3 illustrates this effect by showing the variance of $U_{L}$ value with receiver size. The variance is larger for the reference trough receiver than the evacuated recelver because conductive/convective losses do not increase directly with absorber diameter, while radiation losses nearly do. Largerdiameter absorbers are shown to result in smailer heat losses per unit absorber area.

While the absorber tube diameter is fixed, the receiver glazing diameter is sized to minimize the conductive/convective losses. Too small a glass diameter (small gap) results in excessive conduction losses, whereas too large a 


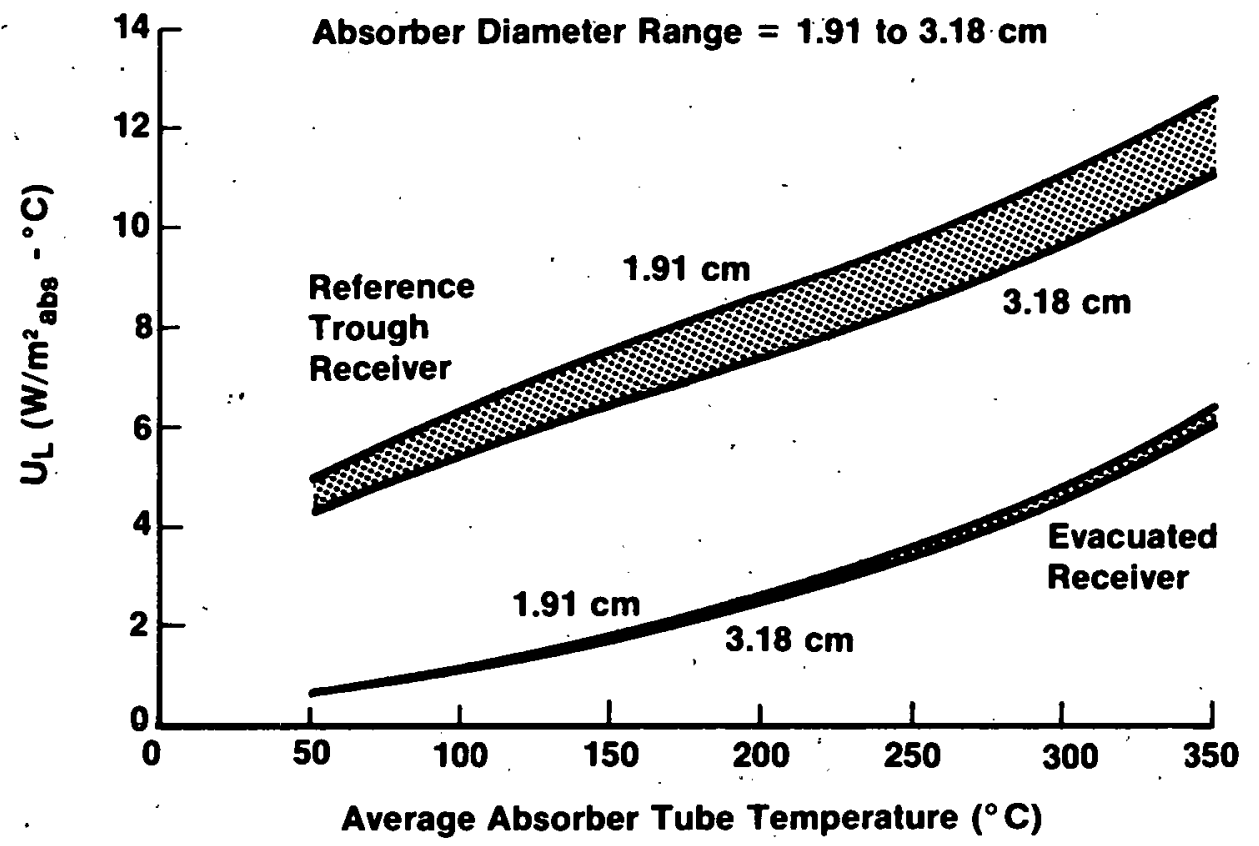

Figure 2-3. Heat-Loss Coefficient Variance with Absorber Diametı

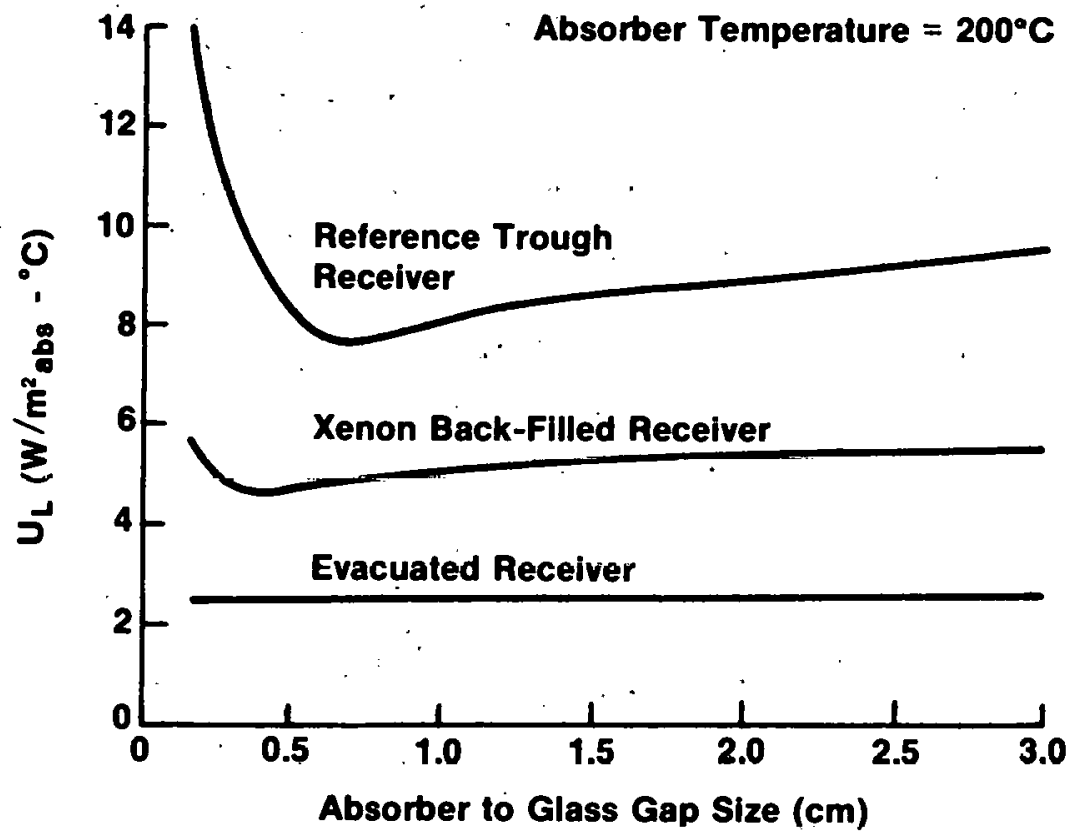

Figure 2-4. Heat-Loss Coefficient vs. Gap Size - 
glass diameter (large gap) results in excessive convection losses. The significance of annulus gap slze is shown in Fig. 2-4. For an evacuated recelver, glass diameter sizing is not thermally significant because no conduction or convection occurs in. the annulus.

\subsection{OPTIMIZATION OF GEOMETRIC CONCENTRATION RATIO}

The geometric concentration ratio is defined as the ratio of collector aperture area to receiver surface area. For a parabolic trough with cylindrical receiver, the concentration ratio is defined as

$$
\mathrm{C}=\frac{\mathrm{W}}{\pi \mathrm{D}_{\mathrm{abs}}}
$$

Since we wish to evaluate thermal and optical performance improvements on an equal basis, we invoke the concept of concentration ratio optimization [10]. The concentration ratio is optimized to minimize the sum of both thermal and optical losses for a given collector configuration and receiver temperature. Lower concentration ratios permit a greater amount of the reflected energy to intercept the receiver tube. However, low concentration ratios increase the absorber tube surface area, relative to the aperture area, and result in increased thermal loss. Conversely, high concentration ratios reduce thermal losses but increase optical 1osses. An absorber tube diameter of $2.54 \mathrm{~cm} 1 \mathrm{~s}$ held constant while the aperture width is sized by the optimum concentration ratio.

Thermal inputs to the optimization consist of heat-loss coefficients expressed as U-values based on receiver area and receiver temperature. The optical inputs consist of the optical properties of materials and manufacturing processes expressed as rms standard deviation values of beam spreading. The following errors contribute to the imperfect optics of a parabolic trough: mirror. nonspecularity, slope or contour error, tracking error, and displacement error as caused by the mislocation of the receiver tube with respect to the mirrors.

The concentration ratio is optimizèd to maximize annual energy delivery at its specific operating temperature. Optimizing for a clear equinox day (clearness index $\mathrm{K}_{\mathrm{h}} \simeq 0.75$ ) corresponds very closely to the annual energy optimum. Therefore, clear sky data for the equinox, with the ambient temperature at the yearly average, is employed for the concentration ratio optimization.

The methodology is taken from Ref. 10. Briefly, the imperfect optics and the sun shape are characterized by a Gaussian distribution. Therefore, a total all-day average beam spreading $\left\langle\sigma_{\text {total }}\right\rangle$ is the rms value of the optical errors and sun shape expressed aș:

$$
\left\langle\sigma_{\text {total }}\right\rangle=\left(\left\langle\sigma_{\text {optical }}\right\rangle^{2}+\left\langle\sigma_{\text {sun }}\right\rangle^{2}\right)^{1 / 2}
$$




$$
\begin{aligned}
& \left\langle\sigma_{\text {optical }}\right\rangle^{2}=\text { all-day average value of optical beam spreading }\left(90^{\circ}\right. \text { rim angle) } \\
& =4 \sigma_{\operatorname{con}_{\perp}}{ }^{2}+0.215\left\langle\tan ^{2} \theta\right\rangle \times\left(4 \sigma_{\operatorname{con}_{\|}}{ }^{2}+\sigma_{\operatorname{spec}_{\|}}{ }^{2}\right) \\
& +\sigma_{\text {track }}{ }^{2}+\sigma_{\text {disp }}{ }^{2}+\sigma_{\text {spec }_{\perp}}{ }^{2} \\
& \left\langle\sigma_{\text {sun }}\right\rangle^{2}=\text { all-day average value of sun size } \\
& =\sigma_{\text {sun, noon }} 2 \frac{\int_{0}^{\omega} \frac{I_{b}(\omega) \cos \theta(\omega) d \omega}{\cos ^{2} \theta(\omega)}}{\int_{0}^{\omega} I_{b}(\omega) \cos \theta(\omega) d \omega} \text {. }
\end{aligned}
$$

The size of the sun at noon and at $0^{\circ}$ incidence angle expressed as an rms value is $2.8 \mathrm{mrad}$ for line focus geometry as calculated from the Lawrence Berkeley Laboratories circumsolar data base [11]. Note that, in the calculation of all-day average sun size, a factor of $\cos \theta$ appears, since the apparent sun size varies as the inverse of the cosine of the incidence angle.

An all-day critical intensity ratio is determined by the a11-day available insolation, heat-loss rate, all-day optical efficiency, shading of mirrors by glass annulus, and the all-day average diffuse energy. This ratio is given by

$$
\langle\mathrm{X}\rangle=\frac{1}{\left\langle\mathrm{I}_{\mathrm{b}} \cos \theta\right\rangle}\left(\frac{\dot{\mathrm{Q}}_{\mathrm{L}}}{\langle\rho \tau \alpha\rangle}+\left\langle\dot{\mathrm{Q}}_{\mathrm{s}}\right\rangle-\left\langle\mathrm{I}_{\mathrm{d}}\right\rangle\right) .
$$

The optimum concentration ratio $\mathrm{C}_{0}$ can be determined as a function of the critical intensity ratio $\langle X\rangle$ and the total optical error $\left\langle\sigma_{\text {total }}\right\rangle$. A curvefit of this relationship (from Fig. 5-1 of Ref. 10) for a 90 rim angle parabolic trough is:

$$
\begin{aligned}
c_{0}=\frac{1}{\left\langle\sigma_{\text {total }}\right\rangle} & \left\{0.0585+0.816\left(\sigma_{\text {total }}\langle\mathrm{X}\rangle\right)^{1 / 3}-2.02\left(\sigma_{\text {total }}\langle\mathrm{X}\rangle\right)^{2 / 3}\right. \\
& \left.+2.99 \sigma_{\text {total }}\langle\mathrm{X}\rangle\right\},
\end{aligned}
$$

where $C_{0}=$ optimum concentration ratio.

The value of the optimum concentration ratio is strongly dependent upon the level of the heat loss and the degree of optical quality. For example, the 
values of $\mathrm{C}_{\mathrm{o}}$ range from 11 at $50^{\circ} \mathrm{C}$ to 29 at $350^{\circ} \mathrm{C}$ for the reference parabolic trough in Denver. When the receiver heat loss is reduced by evacuating the receiver annulus, the $C_{o}$ range is from 9 to 20 . If the optical quality is improved by decreasing the contour error, the optimum concentration ratio increases and was found to range from 18 at $50^{\circ} \mathrm{C}$ to 37 at $350^{\circ} \mathrm{C}$.

\subsection{OPTICAL ANALYSIS}

In order to accurately predict the performance of a parabolic trough concentrator, one must know the variation of optical efficieucy with angle of incidence between the receiver and the incoming radiation. There are several factors that contribute to the decrease of optical efficiency with increasing incidence angle. These factors include, in part, the angular dependence of glass annulus transmittance and receiver absorptance. Also, the intercept factor (defined as that fraction of rays incident upon the aperture that reach the receiver) decreases with incidence angle. This decrease in optical efficiency by the intercept factor is brought about in two ways. First, there is beam spreading due to longitudinal contour and nonspecularity errors. Secondly, the apparent sun image becomes wider due to the longer reflected path length.

The calculation of the intercept factor $\gamma$ involves the convolution of the geometric angular acceptance function for a parabolic trough with a Gaussian distribution that accounts for total beam spreading (i.e., both optics and sun size).The intercept factor $\gamma$ can be expressed as a function of the product of $\sigma_{\text {total }}$ and $C$. For a $90^{\circ}$ rim angle trough, the intercept factor can be calculated with the following equation (curve-fit to Fig. 4-1 of Ref. 10):

for $\sigma=\sigma_{\text {total }}$,

$$
\begin{aligned}
\gamma[\sigma C]= & 1 \text { for } \sigma C<0.134 ; \\
= & {\left[0.932+1.27 \sigma C-6.54(\sigma C)^{2}+5.91(\sigma C)^{3}\right] } \\
& \text { for } 0.1311<\sigma C<0.15 ; \\
= & {\left[1.38-2.01 \cup C+1.35(u C)^{2}-0.348(u C)^{3}\right] } \\
& \text { for } \sigma>0.45 \text {. }
\end{aligned}
$$

The angular dependence of transmittance and absorptance are extracted from data contained in the appendix of Ref. 12. The effect on absorptance from the distribution of incidence angles circumferentially on the receiver tube is included as well. By neglecting this distribution of incidence angles around the tube, one finds a relative error between 1 and $2-1 / 2 \%$ in yearly performance. The incidence angle modifier $\mathrm{K}(\theta)$ defines how the optical efficiency decreases with incidence angle, relative to the trough's normal incidence optical efficiency. The incidence angle modifier at a given incidence angle $\theta$ is defined as:

$$
\dot{K}(\theta)=\frac{(\rho \tau \alpha \gamma)[\theta]}{(\rho \tau \sigma \gamma)[\theta=0]}
$$


Note that the denominator is the optical efficiency at normal incidence, 1.e. $n_{0}$.

Experimental data for incidence-angle modifiers (Ref. 13) agrees well with our analytical determination.

\subsection{YEARLY PERFORMANCE PREDICTION}

The yearly performance prediction is based on a simple procedure derived by M. Collares-Pereira and A. Rabl [1]. Basically, the model computes the energy delivery of a parabolic trough. for the central day of each month of the year. The concept of utilizability is incorporated to account for both heat loss and the variability of weather.

Input data for the yearly performance prediction consists of receiver temperature and heat-loss coefficlent, optimum concentration ratio, optical efficiency at normal incidence, and the incidence-angle modifier for the particular. parabolic trough in question. Climatological data includes latitude, monthly clearness indices, and amblent temperatures extracted from the appendix of Ref. 14.

The amount of insolation available to the parabolic trough is determined by the Liu and Jordan method, utilizing the improved correlations of Ref. 15. The fundamental parameter is the clearness index $k_{h}$, which is the ratio of terrestrial, $\mathrm{H}_{\mathrm{h}}$, over extraterrestrial, $\mathrm{H}_{0}$, daily hemispherical irradiation on a horizontal surface. The clearness index can be expressed as $\mathrm{K}_{\mathrm{h}}=\mathrm{H}_{\mathrm{h}} / \mathrm{H}_{0}$.

The al1-day available isolation $\mathrm{H}_{\text {coll }}$ is calculated by integrating the product of the beam insolation and the cosine of the incidence angle on the collector in the following way:

$$
H_{c u 11}=\frac{2 t_{c}}{\omega_{c}} \int_{0}^{\omega_{c}} I_{b} \cos \theta d \omega .
$$

The dally heat loss of a collector can be expressed in terms of a critical intensity ratio $X$, which is the ratio of the daily heat loss to that fraction of the incident solar energy received by the absorber. This ratio is given as

$$
X=\frac{U_{L}\left(T_{a b s}-T_{a m b}\right) 2 t_{c}}{\left\langle\eta_{0}\right\rangle C \cdot H_{c o l l}}
$$

The term $\left\langle n_{0}\right\rangle$ is the day-long average optical efficiency. The calculation of $\left\langle n_{0}\right\rangle$ requires weighting the product of the optical efficiency at $0^{\circ}$ incidence, 
$\eta_{0}$, and the incidence angle modifier, $K(\theta)$, to the available beam insolation $\mathrm{I}_{\mathrm{b}} \cos \theta$ in the following fashion

$$
\left\langle n_{0}\right\rangle=\frac{\int_{0}^{\omega}{ }_{c}\left(I_{b} \cos \theta\right) \eta_{0} K(\theta) d \omega}{\int_{0}^{\omega}{ }_{c}^{\omega} I_{b} \cos \theta d \omega} .
$$

A utilizability function $\phi$ is defined to account for both the daily heat loss and the variability of the weather. This utilizability function for a concentrating collector is a function of clearness index $\mathrm{K}_{\mathrm{h}}$ and critical intensity ratio $\mathrm{X}$ :

$$
\phi\left(k_{h}, x\right)=1-\left(0.049+1.044 K_{h}\right) x+0.341 k_{h} x^{2}
$$

The monthly energy delivery of the collector is computed by the product of the day-long average optical efficiency $\left\langle\eta_{0}\right\rangle$, utilizability $\phi$, and available insolation $\mathrm{H}_{\mathrm{co11}}$ :

$$
Q_{\text {month }}=30.44 \mathrm{H}_{\text {coll }}\left\langle\eta_{0}\right\rangle \phi
$$

where 30.44 is the average number of days per month.

The value of the cut-off hour angle $\omega_{c}$ is optimized by iteration in order to maximize the monthly output of the solar collector.

Finally, the yearly energy delivery Qyear of the collector is simply found by summing all the monthly energy, values.. 


\author{
SECTION 3.0
}

\title{
RESULTS
}

\subsection{INDIVIDUAL IMPROVEMENTS.}

Normalized Performance Indices (NPI) for individual improvements are presented in Figs. 3-1,2,3 for east-west, north-south, and polar mounted troughs, respectively. The results are based on Denver's climatological data, where NPI is calculated in the following way:

$$
N P I=\frac{Q_{\text {year, }} \text { improved collector }}{Q_{\text {year, reference collector }}} \text {. }
$$

Whereas all the Normalized Performance Indices increase with temperature, the rate of increase varies. Improvements associated with increased optical efficiency increase their. Normalized Performance Indices less rapidly than improvements âssociated with thermal losses.

At Low temperature, thermal losses are small, and therefore further reductions are relatively less significant. Optical efficiency improvements dominate in this range and a back-silvered glass reflector results in the largest low-temperature performance increase of the improvements considered in this study. An increased recelver glazing transmittance is the second most significant improvement at low operating temperatures. Increasing the selective surface absorptance has only a small impact, because black chrome absorptance has been well developed and little further gain is possible.

At higher operating temperatures, thermal losses increase and become more significant to trough performance. Above $150^{\circ} \mathrm{C}$, the performance benefit of an evacuated receiver is larger than for any other improvement considered in this study. A kenon back-filled receiver is also shown to significantly increase trough energy delivery with increased operating temperatures. A reduction in concentrator slope error behaves much like a thermal improvement. The reason for this is that slope error reductions result in more precise concentrator optics and permit high concentration ratio troughs. This reduces the size of the receiver relative to the concentrator and in effect diminishes thermal losses. Thus, reduced slope error becomes a dominant factor in trough performance at high operating temperatures. The merit of heat mirror coated receiver glazings depends strongly on temperature level. Below $275^{\circ} \mathrm{C}$, the reduction in thermal losses due to the heat mirror is overshadowed by its large reduction in optical efficiency, and performance is degraded.* Above $275^{\circ} \mathrm{C}$, it offers moderate benefit with nonevacuated receivers. Decreased selective surface emittance also offers a meaningful performance gain only for hightemperature operation.

*Although using heat mirror coated receiver glazings in conjunction with black chrome is not effective, they may be utilized effectively in place of black chrome or other selective surfaces. 


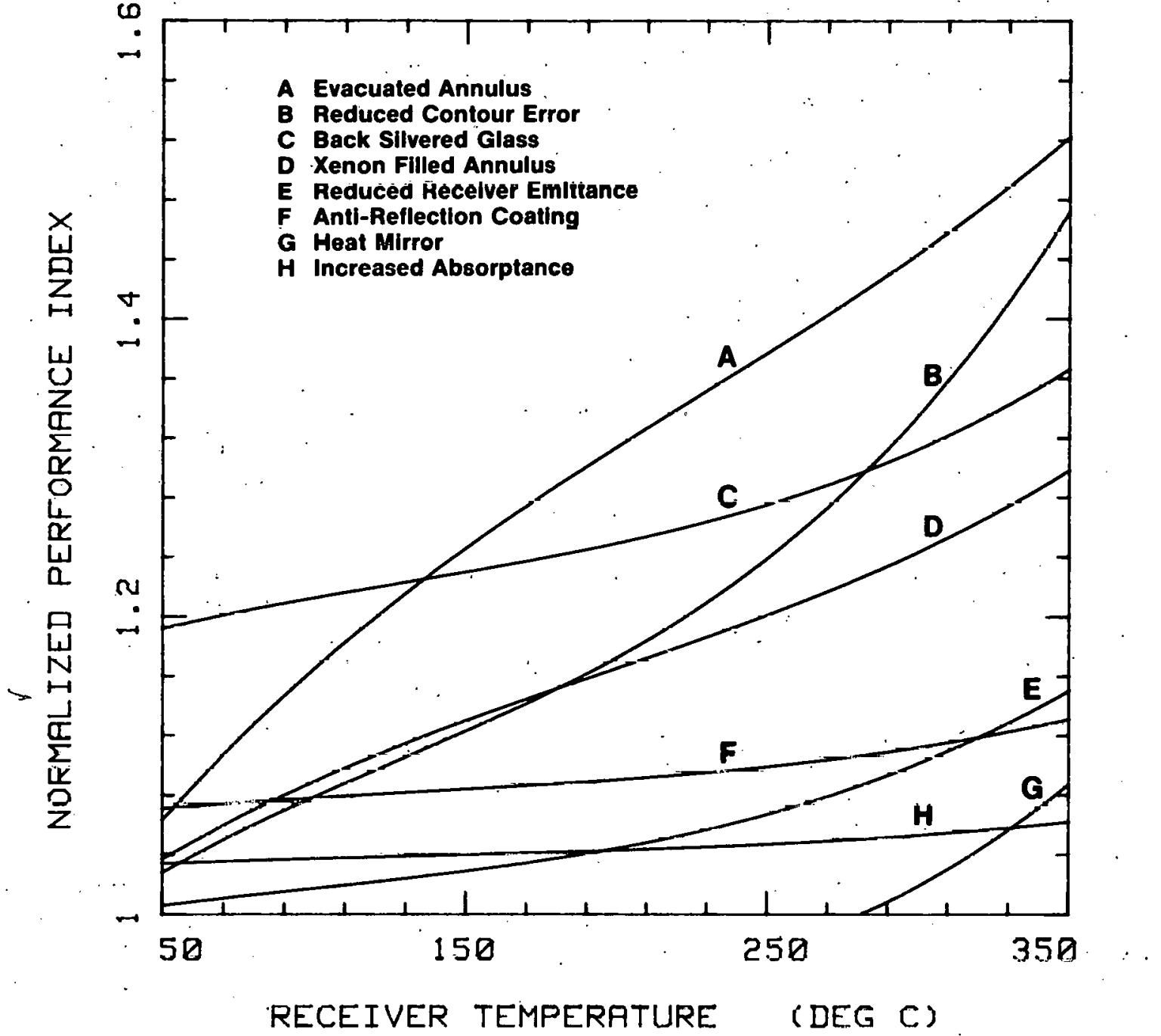

Flgure 3-1. Normalized Performance Index for Improved East-West Rotational Axis Parabolic Troughs 


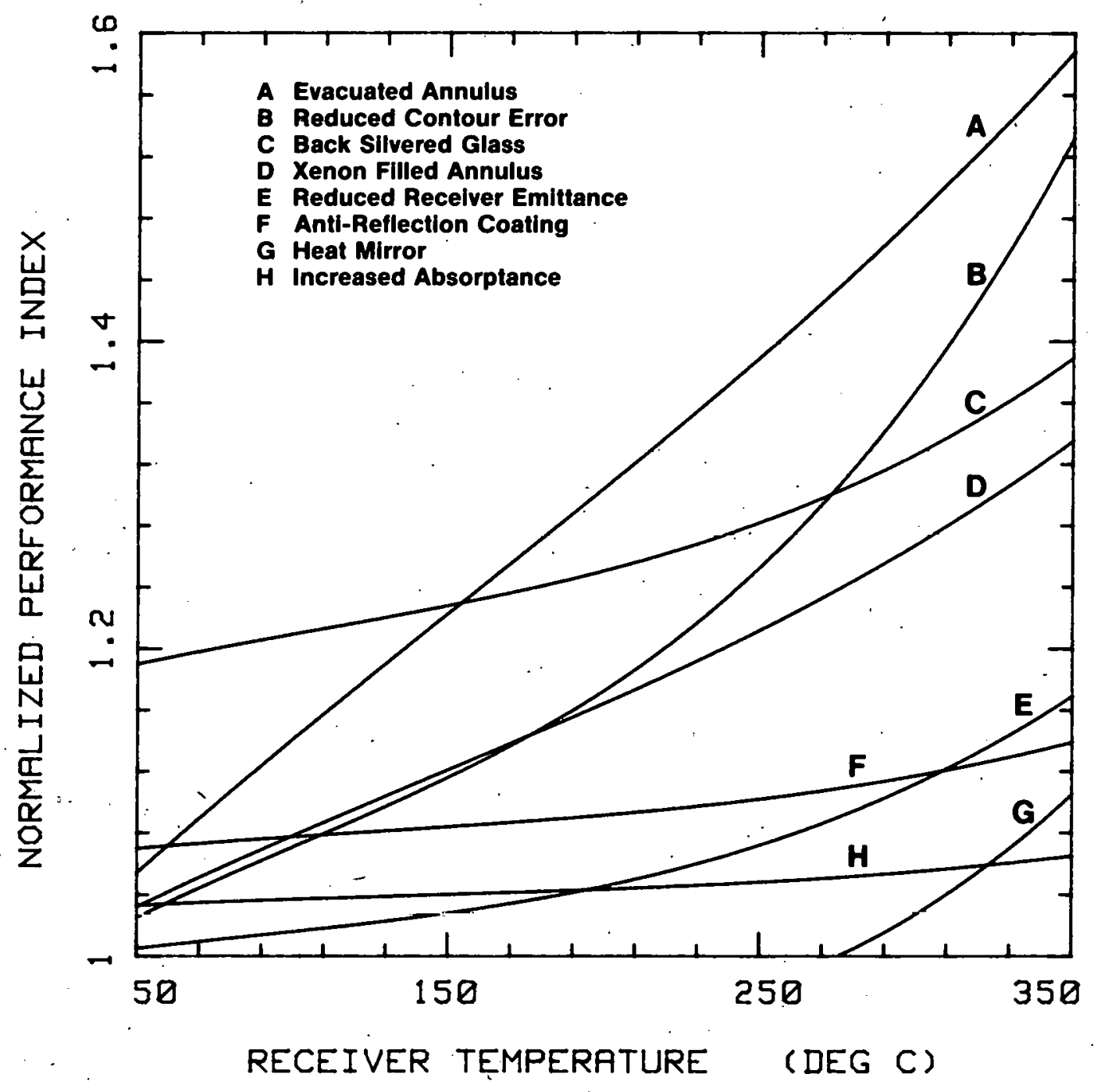

Figure 3-2. Normalized Performance Index for Improved North-South Rotational Axis Parabolic Troughs 


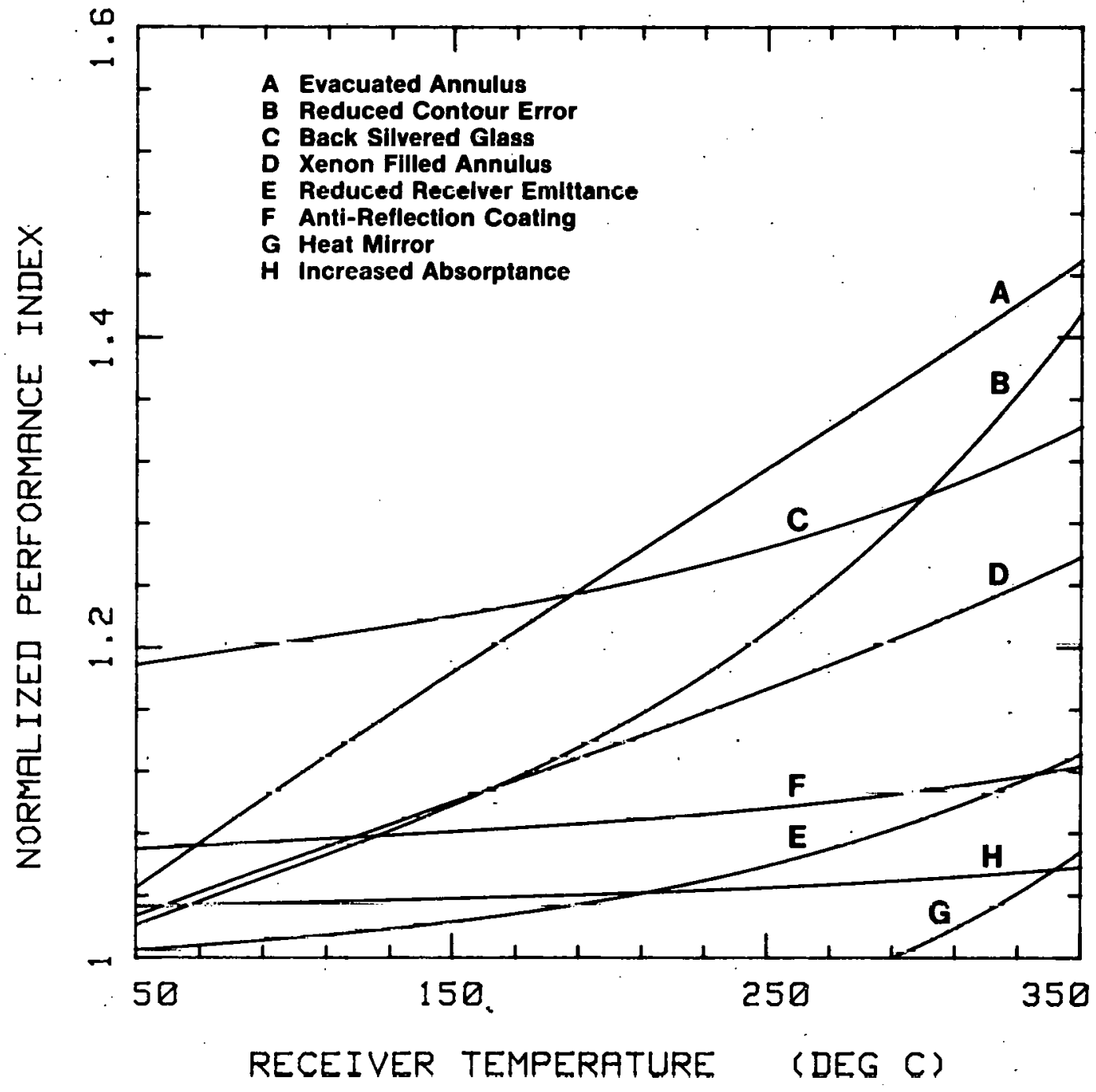

Figure 3-3. Normalized Performance Index for Improved Polar Axis Parabolic Troughs 


\subsection{COMBINED IMPROVEMENTS}

This section provides a method of determining the NPI for one or more parabolic trough improvements. It can be used to evaluate improvements other than those we have considered, or to evaluate an improvement for a parabolic trough other than that defined by the reference trough. The NPI for a given set of improvements is the ratio of the annual collection efficiency of the improved trough to the annual collection efficiency of the unimproved (reference) trough. This section provides a method of graphically determining a parabolic trough's annual collection efficiency, given its characteristics.

Annual collection efficiency can be expressed as a function of three generically grouped terms that are easily computable. The first term, $\rho \tau \alpha$, is simply the product of concentrator reflectance, receiver glazing transmittance, and receiver tube selective surface absorptance. The second term is the receiver heat-loss rate $\dot{Q}_{L}$ at the operating temperature of the trough. The final term is the effective optical error total at normal incidence that results from 1mperfect tracking and concentrator optics. The three terms are defined in detail below.

$$
\begin{aligned}
\rho \tau \alpha= & (\text { hemispherical reflectance) } \times \text { (receiver glazing transmittance } \\
& \text { at normal incidence) } \times \text { (receiver tube selective surface ab- } \\
& \text { sorptance at normal incidence); } \\
\dot{Q}_{\mathrm{L}}= & \mathrm{U}_{\mathrm{L}}\left(\mathrm{T}_{\mathrm{abs}}-\mathrm{T}_{\mathrm{amb}}\right)=\text { heat-1oss rate from receiver in watts per } \\
& \text { square meter of absorber tube area; } \\
& \left(4 \sigma_{\text {con }}^{2}+\sigma_{\text {track }}^{2}+\sigma_{\text {disp }}^{2}+\sigma_{\text {spec }}^{2}\right)^{1 / 2} \text { expressed in milli- } \\
& \text { radians (note that sun size is not included in this term). }
\end{aligned}
$$

Annual collection efficlency is defined as the ratio of the annual collected energy to the annual beam insolation falling on the collector aperture from sunrise to sunset. Trough end losses and row-to-row shading losses are not included, because they are a function of collector field geometry. The calculation of annual collected energy essentially follows the procedure of Fig. 2-1. Thus, the annual collection efficiencies are for $90^{\circ}$ rim angle troughs with optimized concentration ratios.

In order that the optical error terms be graphically represented by a single quantity, the assumption that total optical error is dominated by concentrator slope error has been made. This assumption allows the calculation of the effective all-day optical error total for a $90^{\circ}$ rim angle trough as:

$$
\left\langle\sigma_{\text {optical }}\right\rangle=\left[\sigma_{\text {optical }}^{2}\left(1+0.215\left\langle\tan ^{2} \theta\right\rangle\right)\right]^{1 / 2} .
$$

This definition allows the graphical representation of annual collection efficlency with simply one optical error quantity, $\sigma_{\text {optical }}$. The error in annual collection efficiency due to this assumption is generally less than $1 \%$. 
The annual collection efficiency graphs are presented in Figs. 3-4,5,6 for east-west, north-south, and polar mounts, respectively. Since the $\rho \tau \alpha$ term is presented in increments of 0.1 , interpolation is generally required to determine annual collection efficiencies. from the graphs. The results are based on Denver's climatological data, just as the Normalized Performance Indices are: Annual collection efficiencies are slightly higher for climates sunnier than Denver and slightly lower for cloudier climates. The performance limit curves are shown to provide a line of reference. These lines indicate the absolute annual collection efficiency that a perfect $\left(\rho \tau \alpha=1, \sigma_{\text {optical }}=0\right)$ trough could attain, given its thermal loss.

The Normalized Performance Index tor a given Improvement or comblned 1mprovements can be calculated by determining the annual collection efficiencies of both a reference trough and an improved trough. The ratio of these annual collection efficiencies defines the Normalized Performance Index. Fig. 3-7 presents Normalized Performance Indices for several combinations of improvements. The NPI values have been generated with respect to the reference trough with east-west mount. The performance benefits of combined improvements are dramatic. Many improvements complement each other, and the resulting performance increase exceeds the sum of the individual performance increases. For example, an improvement such as a back-silvered glass reflector is complemented by a thermal loss improvement such as an evacuated receiver. On the other hand, some improvements may largely negate the potential gains of another improvement. The combination of reduced concentrator slope error and an evacuated receiver is an example of such a combination. The reduced thermal losses of an evacuated receiver tends to minimize the effect of slope errors, since slope errors are shown to Increase ln slgillicance with higher receiver heat loss.

\subsection{VALIDATION OF METHOD}

The utilizability method of predicting the thermal performance of parabolic troughs was validated by comparing the results to those obtained from the Typical Meteorlogical Year (TMY) data base (Kef. 16). The values for munlhly clearness index $\mathrm{K}_{h}$ and monthly diffuse to hemispherical ratio $\mathrm{H}_{\mathrm{d}} / \mathrm{H}_{\mathrm{h}}$. for the utilizability method were calculated from the hourly TMY data base.

The first comparison evaluates the yearly total available insolation on the aperture of a parabolic trough for four mounting orientations: two-axis, polar, north-south, and east-west, and for three cities, Albuquerque, Bismarck, and Dodge City. In all cases, the utilizability method overpredicts the available insolation. The relative errors in percent between the two models are displayed in Table 3-1. 

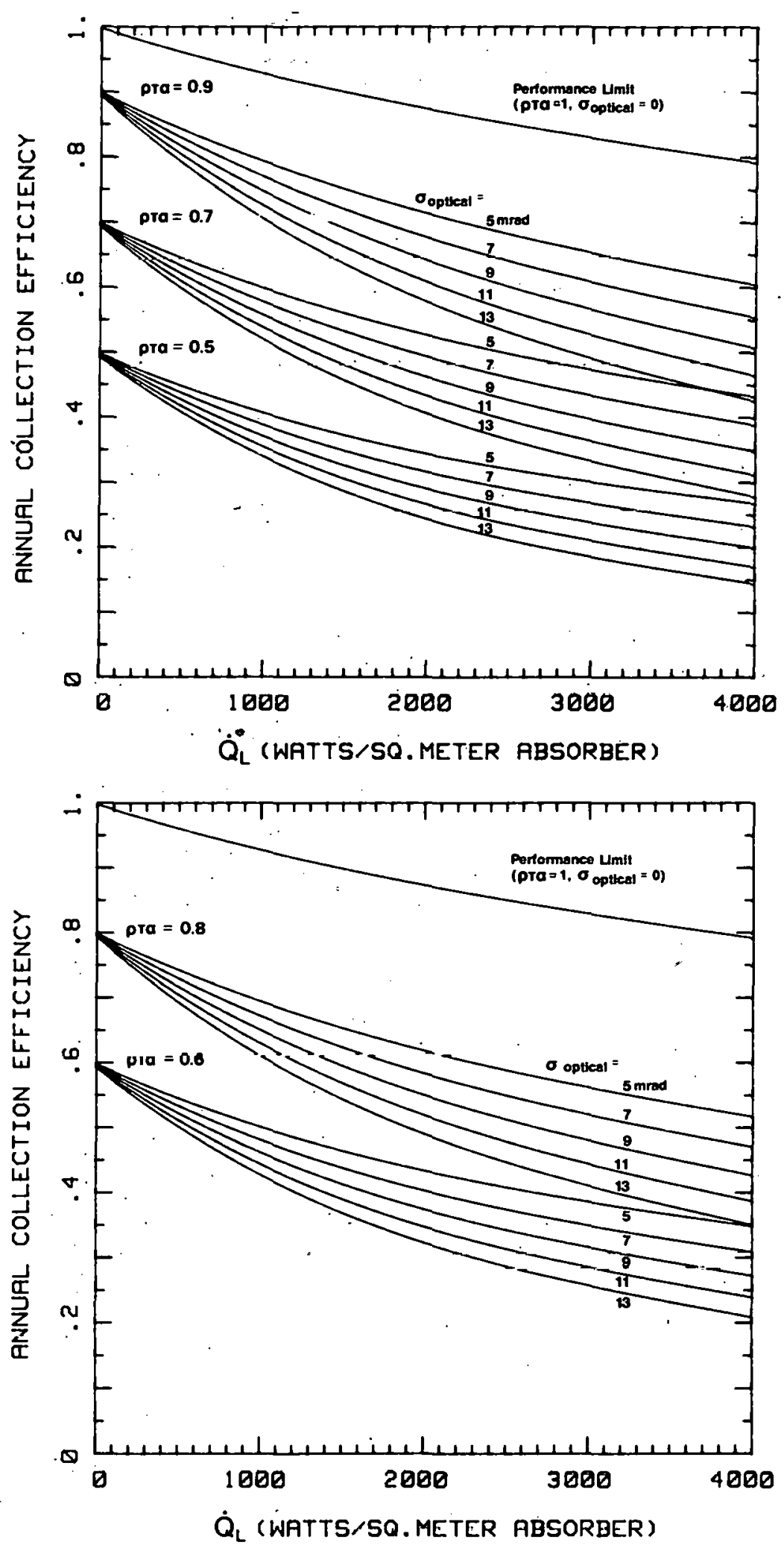

Figure 3-4: Annual Collection Efficiency of East-West Rotational Axis Parabolic Trough vs. Recelver Heat-Loss Rate 

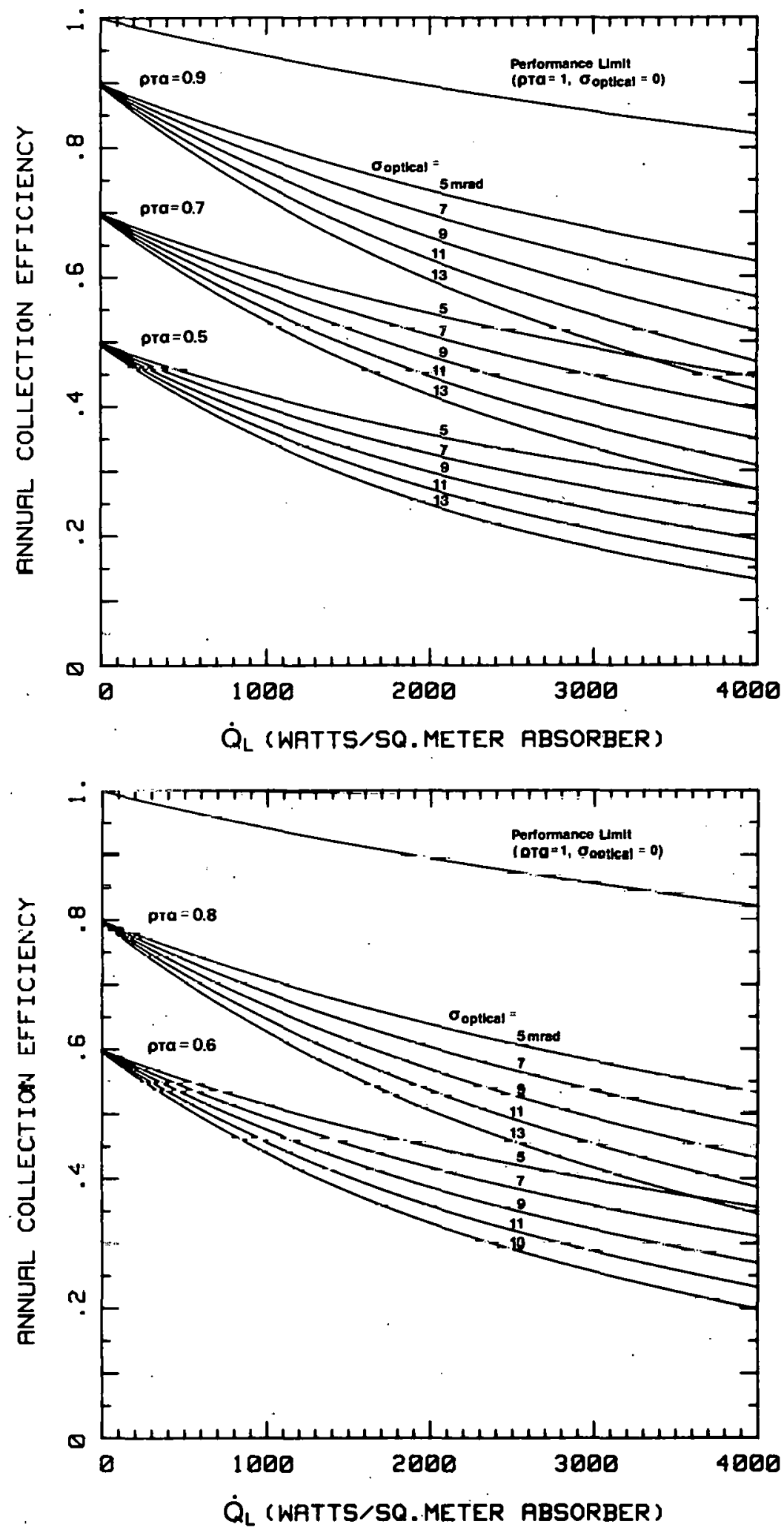

Figure 3-5. Annual Collection Efficiency for North-South Rotational Axis Parabolic Trough vs. Receiver Heat-Loss Rate 

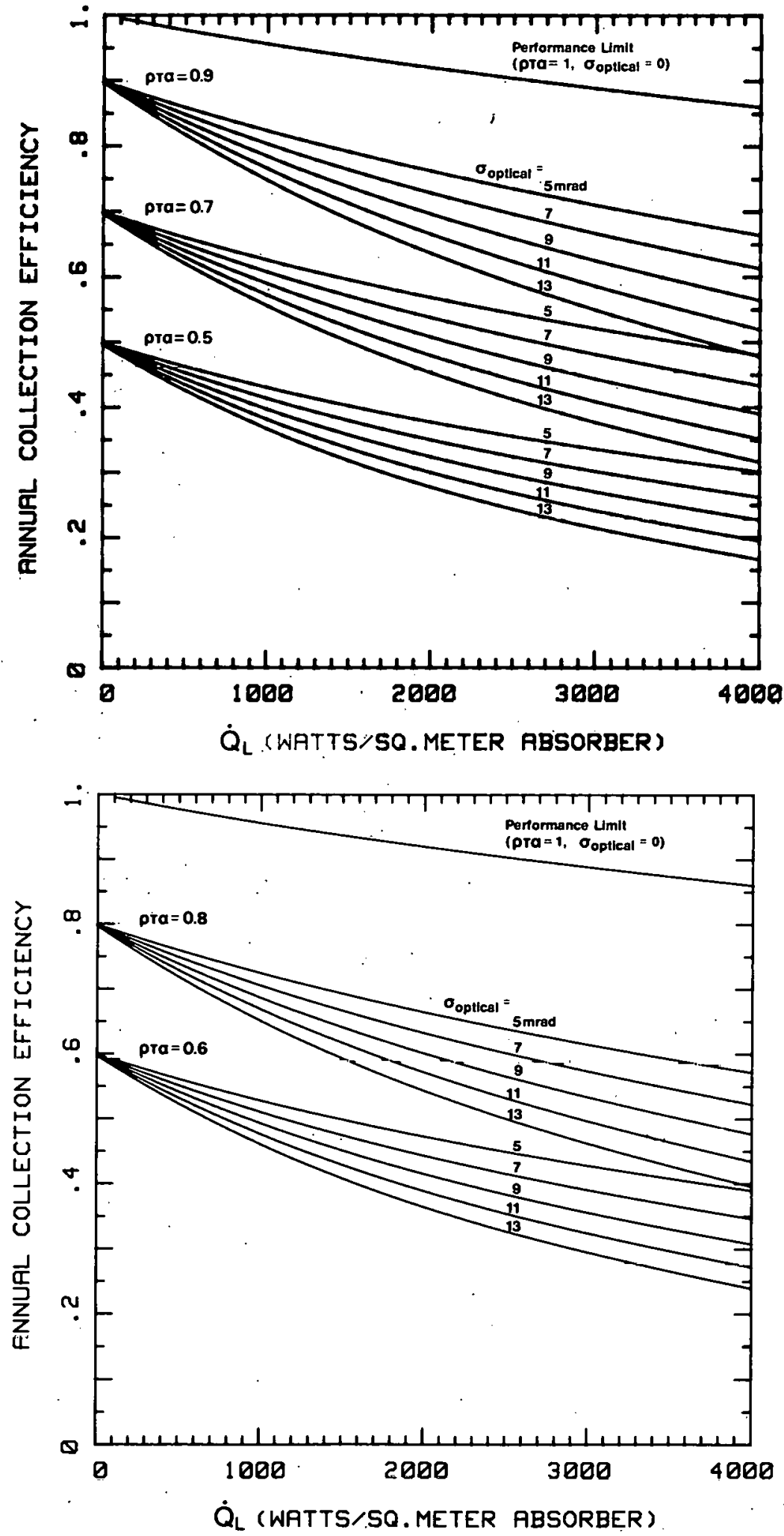

Figure 3-6. Annual Collection Efficiency for Polar Axis Trough vs. Recelver Heat-Loss Rate 


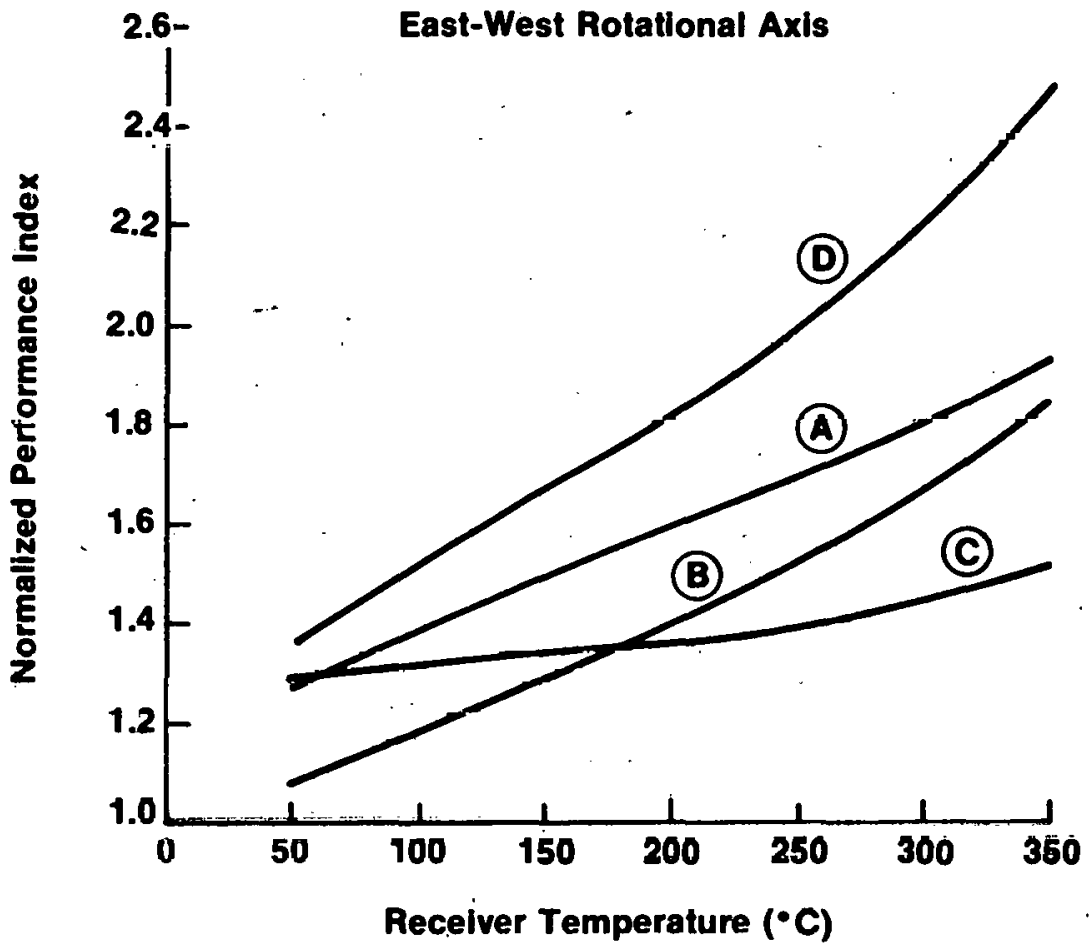
(A) Evacuated Annulus and Back-Silvered Glass
B) Evacuated Annulus and Reduced Contour Error
(C) Back-Silvered Glass and Anti-Reflection Coating
(D) B and C

Figure 3-7. Parabolic Trough Performance Gains with Combined Improvements 
Table 3-1. AVAILABLE INSOLATION RELATIVE ERROR (\%) OF UTILIZABILITY METHOD WITH RESPECT TO TMY DATA

\begin{tabular}{cccc}
\hline & \multicolumn{3}{c}{ City } \\
\cline { 2 - 4 } Mounting & $\begin{array}{c}\text { Albuquerque, } \\
\text { New Mexico }\end{array}$ & $\begin{array}{c}\text { Bismarck, } \\
\text { North Dakota }\end{array}$ & $\begin{array}{c}\text { Dodge City, } \\
\text { Kansas }\end{array}$ \\
\hline 2-ax1s & 6.4 & 5.1 & 7.7 \\
Polar & 6.5 & 6.9 & 7.7 \\
North-South & 8.1 & 8.3 & 8.6 \\
East-West & 0.8 & 1.2 & 1.4 \\
\hline
\end{tabular}

Since our study concerns relative results rather than absolute results for the prediction of thermal performance, a comparison was made for the values of NPI as calculated by the utilizability method and the TMY database. Three collector improvements were considered: increased optical efficiency, increased optical quality, and reduced receiver heat losses. The results indicate that the utilizability method predicts the NPI within $5 \%$ relative error of the NPI prediction performed with TMY data. In all cases, the utilizability method slightly overpredicts the NPI. A graph of the error bars for the three improvements is contained in Fig. 3-8.

\subsection{SENSITIVITY TO CLIMATE}

Since Denver's climate is the basis for both the Normalized Performance Index and the Annual Collection Efficiency calculations, a sensitivity analysis was performed to determine how NPIs vary with climate. Two climatological effects, latitude and clearness index were investigated. The latitude of Denver is $39.4^{\circ}$ north and the average clearness index is 0.67 for the year. Denver's climate was chosen for two reasons: Industrial process heat is most economically feasible in sunny areas such as the Southwest; and NPI values generated for Denver fall in the middle of values generated for Seattle, Washington, Albuquerque, New Mexico, Blue Hill, Massachusetts; and Fort Wayne, Indlana. Error bars are generated for three improvements: reduced concentrator slope error, increased concentrator reflectance, and reduced receiver heat 1oss:

First, let us consider latitudes ranging from $30^{\circ}$ to $45^{\circ}$. The results indicate that the higher the latitude, the greater the NPI; conversely, when the latitude is lower, the NPI is smaller. Furthermore, the results indicate that the NPI varies by less than $44 \%$ from that calculated for a latitude of $39.4^{\circ}$ (Denver). The error bars for latitudes from $30^{\circ}$ to $45^{\circ}$ for the three improvements are contained in Fig. 3-9.

The second and more important climatological effect is the clearness index $\left(\mathrm{K}_{\mathrm{h}}\right)$. Let us conoider ycarly clearness indices. ranging from 0.47 to 0.77. The results indicate that the cloudier the climate, the greater the NPI; conversely, when the climate is sunnier, the NPI is smaller. Furthermore; the results indicate that the NPI varies by less than $\pm 7 \%$ from that calculated for a clearness index of 0.67 (Denver). The error bars for 


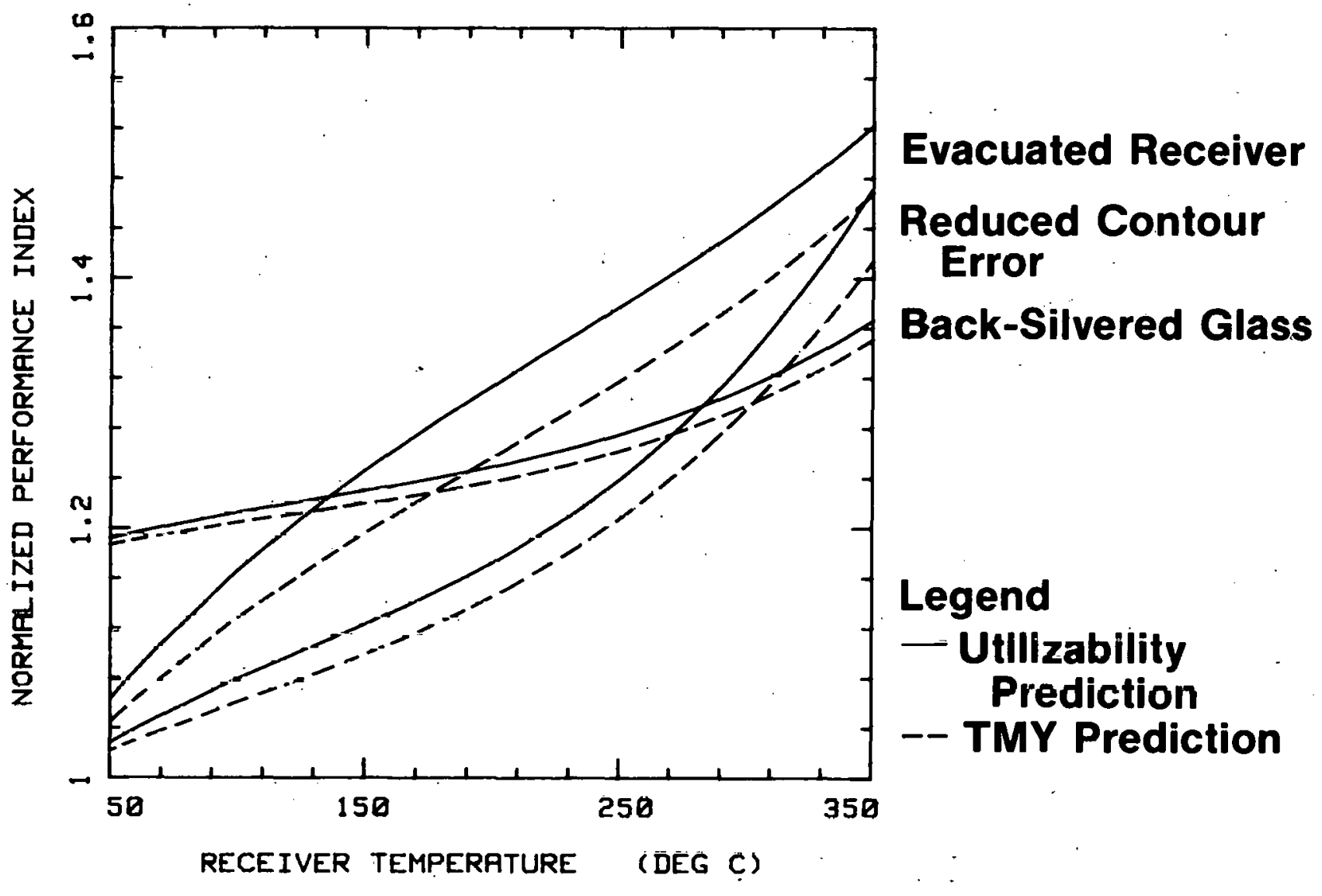

Figure 3-8. Error Bars for Three Collector Improvements Generated from Comparison of Utilizability Method to TMY Data 


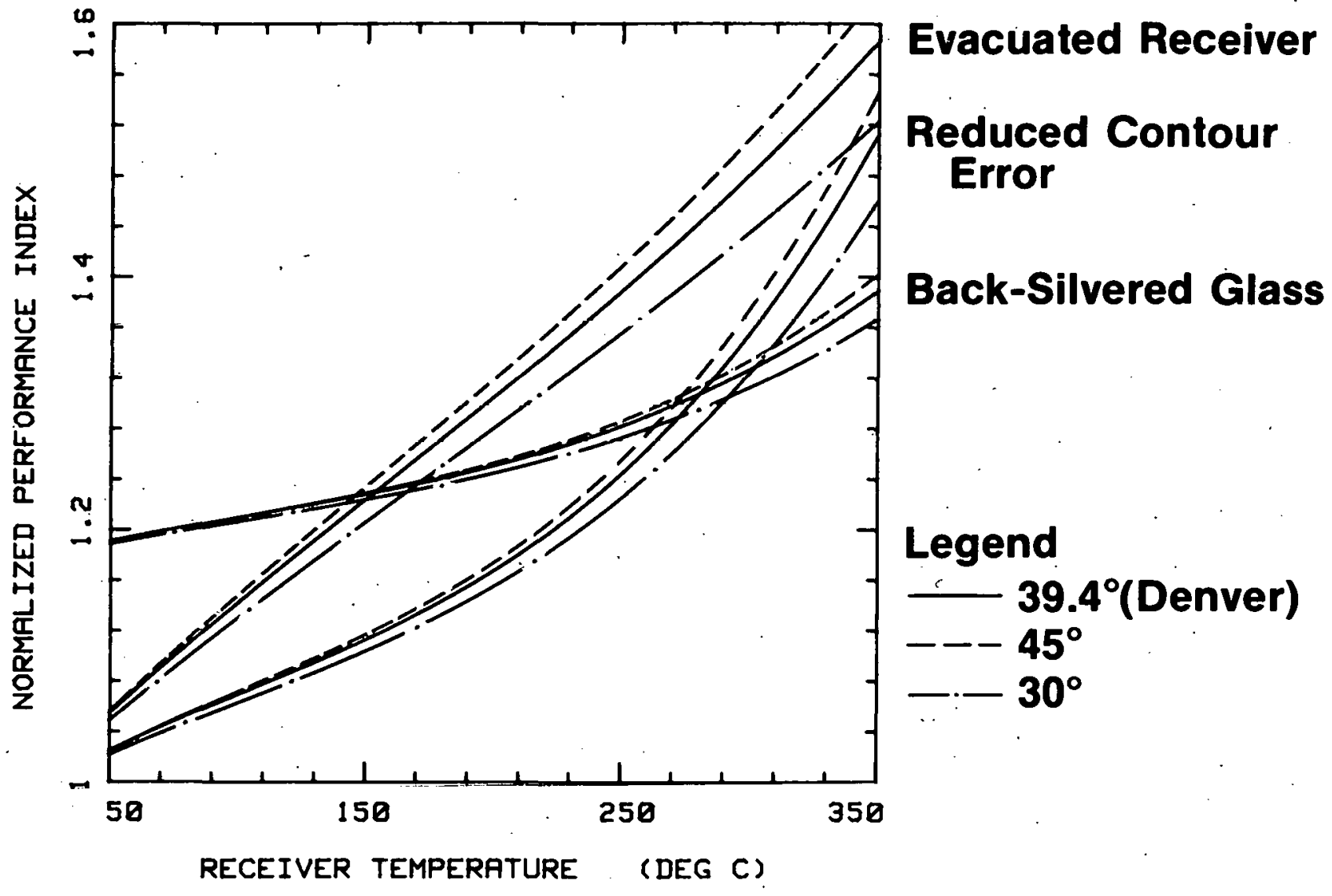

Figure 3-9. Error Bars for Sensitivity of Normalized Performance Index to Latitude 
clearness indices from 0.47 to 0.77 for the three improvements are contained in Fig. 3-10.

\subsection{DISCUSSION}

The magnitude of parabolic trough performance gains that are possible with improvements is very substantial. The gains are due to both the increased operating efficiency of the collector and also the resulting increase in collector operating time. An increase in collector operating efficiency extends operating hours, because the threshold value of insolation required to operate the collector is lowered.

The performance gains, as represented by the Normalized Performance Indices, increase with operating temperature for each of the improvements. This occurs because of the reduction in the absolute magnitude of trough energy delivery as operating temperature increases. For example, a ten point increase in collector efficiency represents a larger percentage increase to a collector operating at high temperature (where the annual efficiency may be $30 \%$ ) than to a collector operating at low temperature (where the annual efficiency may be $60 \%)$.

The Normalized Performance Indices vary with mounting orientation, but the general trends are preserved. At low-temperature operation, improvements that increase the concentrator reflectance, receiver glazing transmittance, or receiver absorptance have the greatest significance. At low temperature, receiver thermal losses are small and further reductions have little impact. Increases in concentrator optical quality are also largely insignificant, because although trough concentration ratios can be increased (with reduced thermal losses per unit aperture area), the resulting decrease in thermai losss is very small at low temperature operation. At higher operating temperatures, parabolic trough energy delivery is significantly affected by receiver thermal 1oss. Improvements that reduce thermal losses tend to outweigh optical efficiency improvements. Also, concentrator optical quality becomes an important parameter. At high operating temperatures, improved optical quality allows higher concentration ratio troughs and a substantial reduction in thermal loss per unit aperture area.

The addition of cost data to the performance data generated in this study will allow the assessment of the improvements on an economic basis. Although some of the improvements necessarily involve increased costs, others are potentially low-cost and would add little to total system cost. Further work in this area will address the economic benefits of improved parabolic troughs. 


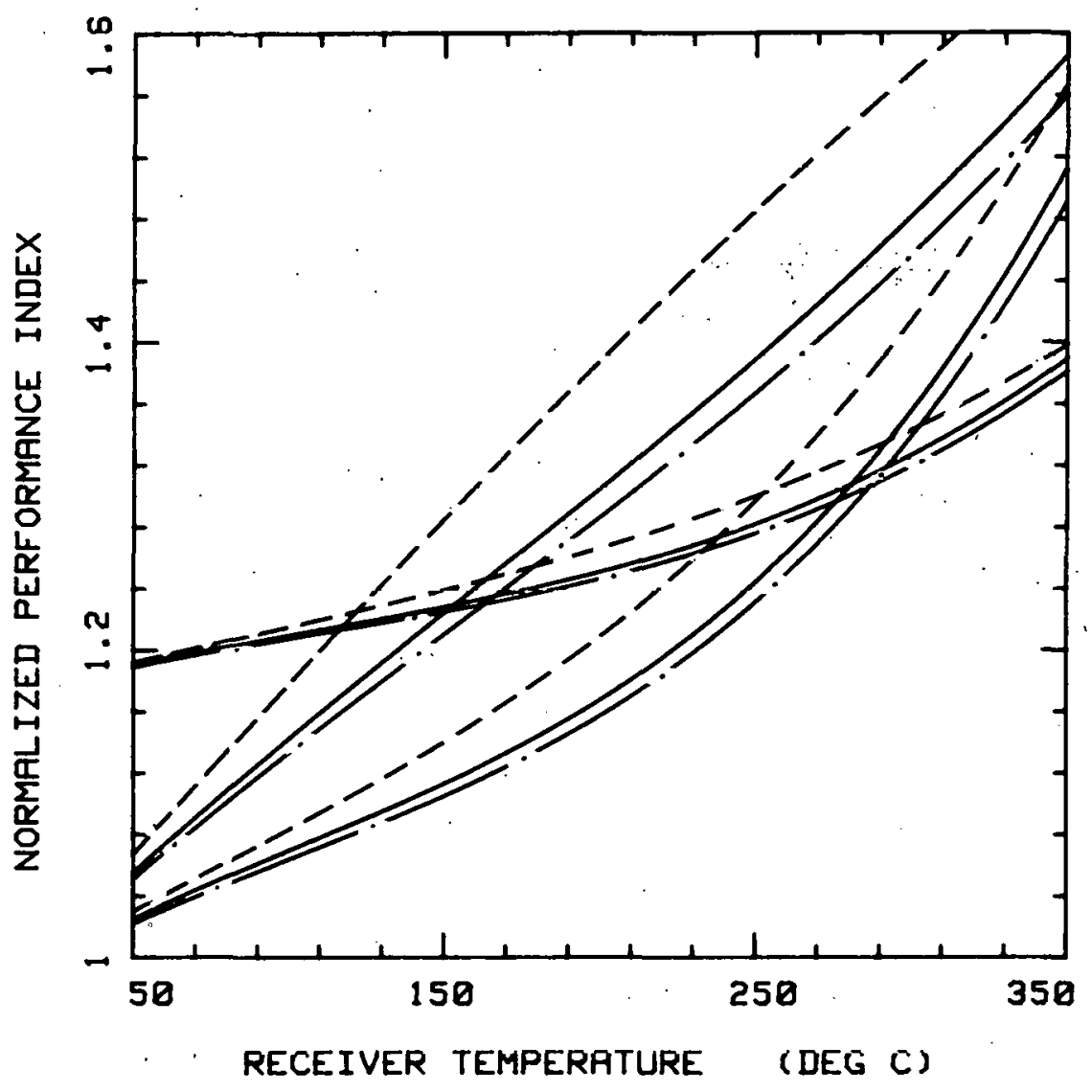

Evacuated Receiver

Reduced Contour

Error

Back-Silvered Glass

Legend

$-K_{h}=0.67$

(Denver)

$-K_{h}=0.47$

$-1 K_{h}=0.77$

Figure 3-10. Error Bars for Sensitivity of Normalized Performance Index to Clearness Index 
SERI幡 
SECTION 4.0

REFERENCES

1. Collares-Pereira, M.; Rabl, A. "Simple Procedure for Predicting Long-Term Average Performance of Nonconcentrating and Concentrating Solar Collectors." Solar Energy. Vol. 23: 1979; pp. 235-53.

2. Rausch, R.; Gupta, B. Exposure Test Results for Reflective Materials. Proceeding from the Institute of Environmental Science Testing Seminar; Gaithersburg, MD; May 1978; pp. 184-87.

3. Allred, R. E.; Miller, D. W.; Butler, B. L. Environmental Testing of Solar Reflector Structures. 1979 ISES Congress; Atlanta, Georgia; May 28-June 1, 1979.

4. Glidden, D. N.; Pettit, R. B. Specular Reflectance Properties of Solar Mirrors as a Function of Incident Angle. 1979 ISES Congress; At lanta, Georgia; May 28-June 1, 197,9.

5. Dudley, V. E.; Workhoven, R. M. Summary Report: Concentrating Solar Collector Test Results (CMTF). SAND 78-0815. Albuquerque, NM. Sandia Laboratories; May.1978.

6. Dudley, 'V. E.; Workhoven, R. M. Summary Report: Concentrating Solar Collector Test Results (CMTF). SAND 78-0977. Albuquerque, NM; Sandia Laboratories; March 1979.

7. Ratzel, A. C.; Hickox, C. E.; Gartling, D. K. "Techniques for Reducing Thermal Conduction and Natural Convection Heat Losses in Annular Receiver Geometries." Journal of Heat Transfer. Vol. 101; February 1979; pp. 108-13.

8. Kühn, T. H.; Goldstein, R. J. "An Experimental Study of Natural Convection Heat Transfer in Concentric and Eccentric Horizontal Cylindrical Annuli." Journal of Heat Transfer. Vol. 100; November 1978; pp. 635-40.

9. Kreith, F. Principles of Heat Transfer. Scranton, Pennsylvania: International Textbook Company; 1965; p. 411.

10. Rabl, A.; Bendt, P.;-Reed, K. A.; Gaul, H. W. Optical Analysis and Optimization of Line Focus Solar Collectors. SERI/TR-34-092. Golden, CO: Solar. Fnergy Research Institute; 1979.

11. Grether, D. F.; Hunt, A.; Wahlig, M. Circumsolar Radiation: Correlations with Solar Radiation. Berkeley, CA: Lawrence Berkeley Labs.; 11 October 1977.

12. Harrison, T.; Bond, G.; Ratzel, A. Design Considerations for a Proposed Passive Vacuum Solar Annular Receiver. SAND 78-0982. Albuquerque, NM: Sandia Laboratories; April 1979. 
13. Gaul, H. W.; Rabl, A. Incidence Angle Modifier and Average Optical Efficiency of Parabolic Trough Collectors. SERI/TP-34-246R • Golden, CO: Solar Energy Research Institute; May 1979.

14. Beckman, W. A.; Klein, S. A.; Duffie, J. A. Solar Heating Design by the F-Chart Method. New York: John Wiley and Sons; 1977.

15. Collares-Pereira, M.; Rabl, A. "The Average Distribution of Solar Radiation: Correlations between Diffuse and Hemispherical and between Daily and Hourly Insolation Values." Solar Energy. Vol. 22;. Pp. 155-64, 1979.

16. Ha11, I. J.; Prairie, R. R.; Anderson, H. E.; Boes, E. C. Generation of Typical Pletcorological Ycaro for 26 SOLMET Stationo. S $\Lambda$ ND 78=1601. Albu= querque, NM: Sandia Laboratories; August 1978. 
NOMENCLATURE

C

$\mathrm{c}_{\mathrm{o}}$

$D_{a b s}$

Dglass , I

Dg1ass, o

$\mathrm{H}_{\mathrm{co} 11}$

$\mathrm{H}_{h}$

$\mathrm{H}_{\mathrm{O}}$

$\mathrm{I}_{\mathrm{b}}$

$\left\langle\mathrm{I}_{d}\right\rangle$

$\mathrm{K}_{\text {gas }}$

$\mathrm{K}_{\text {glass }}$

$\mathrm{K}_{\mathrm{h}}$

$K(\theta)$

$\ell$

$Q_{\text {month }}$

Qyear

$\dot{Q}_{\text {abs,cond/conv }}$

$\dot{Q}_{\text {abs, rad }}$

$\dot{Q}_{\text {envir,conv }}$

$\dot{Q}_{\text {envir,rad }}$ geometric concentration ratio

optimum geometric concentration ratio

absorber tube outside diameter

Inside diameter of recelver glazing

outside diameter of receiver glazing

frradiation incident on collector aperture area on a daily basis

terrestrial daily hemispherical irradiation on horizontal surface

extraterrestrial daily hemispherical irradiation on horizontal surface

beam insolation

al1-day average diffuse energy

thermal conductivity of receiver annulus gas

thermal conductivity of receiver glazing

clearness index

incidence-angle modifier

receiver length

output of collector per unit aperture area per month

output of collector per unit aperture area per year

conductive/convective heat-loss rate from absorber tube to glazing

radiative heat-loss rate from absorber tube to glazing

convective heat-loss rate from receiver glazing to environment

radiative heat-loss rate from receiver glazing to environment 
$\Rightarrow E\left(i^{\prime}=\right.$

$\dot{Q}_{\text {glass,abs }}$

$\dot{Q}_{\text {glass , cond }}$

$\dot{Q}_{L}$

$\dot{Q}_{\text {Loss }}$

$\left\langle Q_{s}\right\rangle$

$t_{c}$

Tabs

$\mathrm{T}_{\text {amb }}$

Tglass, i

Tglass,o

$\mathrm{T}_{\text {sink }}$

$\mathrm{v}_{\mathrm{t}}$.

W

$\mathrm{X}$

$\langle\mathrm{X}\rangle$

$\alpha$

olass

$\gamma$

$\varepsilon_{\text {abs }}$

Eglass,i

Eglass,o

$\eta_{0}$ rate of heat input into receiver glazing due to solar absorptance of glass

conductive heat-loss rate through receiver glazing

heat-loss rate of receiver tube based on receiver area $\left(\mathrm{W} / \mathrm{m}^{2}\right)$

receiver heat-loss rate (watts)

al1-day average shading of reflectors by glass annulus

cut-off time measured as hours from solar noon

absorber tube surface temperature

ambient temperature

temperature of receiver glazing inside surface

temperature of recelver glazing outside surface

radiative sink temperature of environment (average of ambient and effective sky temperatures)

heat-1oss coefficlent, based on absorber tube surface area $\left(\mathrm{W} / \mathrm{m}^{2} /{ }^{\circ} \mathrm{C}\right)$

concentrator aperture width

critical intensity ratio for utilizab111ty

critical intensity ratio for concentration optimization

receiver absorptance

recelver glazlng absurplance

intercept factor

absorber tube emittance

emittance of receiver glazing inside surface.

emittance of reciever glazing outside surface

optical efficiency at normal incidence, which is ( $\rho \tau \alpha \gamma$ ) evaluated at $\theta=0^{\circ}$. 
$\left\langle n_{0}\right\rangle$

$\theta$

$\rho$

$\langle p \tau a\rangle$

$\sigma$

$\sigma_{\text {con }}$

$\sigma_{\text {con }}$

$\sigma_{\text {disp }}$

optical

$\left\langle\sigma_{\text {optical }}\right\rangle$

$\sigma_{\text {spec }}$

$\sigma_{\text {spec }}$

$\sigma_{\text {total }}$

$\left\langle\dot{\sigma}_{\text {sun }}\right\rangle$

$\sigma_{\text {sun, noon }}$

$\left\langle\sigma_{\text {total }}\right\rangle$

$\sigma_{\text {track }}$

$\tau$

$\phi$

$\omega$

$\omega_{c}$

$\left\langle\tan ^{2} \theta\right\rangle$ average optical efficiency on a daily basis

incidence angle

concentrator reflectance

all-day average reflectance-transmittance-absorptance product

Stephan-Bo1tzman constant

rms angular deviation of concentrator from perfect parabola in transverse direction (transverse slope error)

rms angular deviation of concentrator from perfect parabola in longitudinal direction (longitudinal slope.error)

equivalent rms angular spread, which accounts for imperfect placement of receiver

rms angular spread due to all optical errors (at normal Incidence)

rms angular spread due to all optical errors (all-day average)

rms angular spread of reflected beam due to imperfect specularity of reflector material in transverse direction

rms angular spread of reflected beam due to imperfect specularity of reflector material in longitudinal direction

total rms beam spread (a11-day average)

rms angular width of sun (al1-day average)

rms sun shape at noon

total rms beam spread (all-day average)

rms angular spread due to tracking error

receiver glazing transmittance

utilizability

hour angle

cut-off hour angle

all-day average value of $\tan \theta$, weighted to beam insolation 


\begin{tabular}{|c|c|c|c|}
\hline $\begin{array}{l}\text { Document Control } \\
\text { Page }\end{array}$ & \begin{tabular}{|r|r}
$\begin{array}{r}\text { 1. SERI Report No. } \\
\text { TR-632-439 }\end{array}$ & 2 \\
\end{tabular} & 2. NTIS Accession No. & 3. Recipient's Accession No: \\
\hline \multirow{2}{*}{\multicolumn{3}{|c|}{$\begin{array}{l}\text { 4. Title and Subtitle } \\
\text { Long-Term Average Performance Benefits of Parabolic Trough } \\
\text { Improvements }\end{array}$}} & $\begin{array}{r}\text { 5.. Publication Date } \\
\text { March } 1980\end{array}$ \\
\hline & & & 6. \\
\hline \multicolumn{3}{|c|}{$\begin{array}{l}\text { 7. Author(s) } \\
\text { R. Gee; H. Gaul; D. Kearney; A. Rab1 } \\
\text { 9. Performing Organization Name and Address }\end{array}$} & 8. Performing Organization Repr. No. \\
\hline \multicolumn{2}{|c|}{$\begin{array}{l}\text { Solar Energy Research Institute } \\
1617 \text { Cole Boulevard } \\
\text { Golden, Colorado } 80401\end{array}$} & - & $\begin{array}{l}\text { 10. Project/Task/Work Unit No. } \\
\text { Task 非 } 3471.20 \\
\text { 11. Contract (C) or Grant (G) No. } \\
\text { (C) } \\
\text { (G) }\end{array}$ \\
\hline \multirow{2}{*}{\multicolumn{3}{|c|}{ 12. Sponsoring Organization Name and Address }} & $\begin{array}{l}\text { 13. Type of Report \& Period Covered } \\
\text { Technical Report }\end{array}$ \\
\hline & & & 14. \\
\hline
\end{tabular}

15. Supplementary Notẹs

16. Abstract (Limit: 200 words) Improved parabolic trough concentrating collectors will result from better design, improved fabrication techniques, and the development and utilization of improved materials. The difficulty of achieving these improvements varies as does their. potential for increasing parabolic trough performance. The purpose of this analysis is to quantify the relative merit of various technology advancements in improving the long-term average performance of parabolic trough concentrating collectors.

The performance benefits of improvements are determined as a function of operating temperature for north-south, east-west, and polar mounted parabolic troughs. The results are presented graphically to allow a quick determination of the performance merits of particular improvements. Substantial annual energy gains are shown to be attainable. Of the improvements evaluated, the development of stable back-silvered glass reflective surfaces offers the largest performance gain for operating temperatur below $150^{\circ} \mathrm{C}$. Above $150^{\circ} \mathrm{C}$, the development of trough receivers that can maintain a vacuum is the most significant potential improvement. The reduction of concentrator slope errors also has a substantial performance benefit at high operating temperatures

17. Document Analysis

a. Descriptors Parabolic Trough Collectors ; Concentrating Collectors ; Performance Testing : Design ; Fabrication ; Materials ; Thermal Analysis

b. Identifiers/Open-Ended Te:ms

c. UC Categories

$59 b$

18. Availability Statement

National Technical Information Service

U.S. Department of Commerce

5285 Port Royal Road

Springfield, VA 22161

19. No. of Pages

Form No. 8200-13 (6-79)

20. Price

45 